DOI: http://dx.doi.org/10.18309/anp.v1i48.1235

\title{
O MOVIMENTO DE SOBRANCELHAS COMO MARCADOR DE DOMÍNIOS SINTÁTICOS NA LÍNGUA BRASILEIRA DE SINAIS
}

\section{EYEBROW MOVEMENT AS A MARKER OF SYNTACTIC DOMAINS IN BRAZILIAN SIGN LANGUAGE}

\author{
Lorena Mariano Borges Figueiredo \\ Universidade Federal de Minas Gerais Belo Horizonte, Minas Gerais, Brasil \\ Guilherme Lourenço \\ Universidade Federal de Minas Gerais Belo Horizonte, Minas Gerais, Brasil
}

\begin{abstract}
Resumo: Este trabalho objetiva discutir o papel do movimento de sobrancelhas enquanto marcador de domínios sintáticos na Língua Brasileira de Sinais (Libras). A partir da análise de duas narrativas em Libras, identificamos contextos sintáticos em que o levantamento ou abaixamento de sobrancelha ocorre. Alguns desses contextos já foram descritos anteriormente na literatura em análises de outras línguas de sinais e também da própria Libras, a saber: topicalização, orações condicionais, orações relativas e interrogativas do tipo QU- e sim/não. Adicionalmente, encontramos ocorrências de levantamento de sobrancelhas em apontamentos indexicais (com função determinante ou pronominal), em orações adverbiais e em construções que se assemelham a apostos.
\end{abstract}

Palavras-chave: Língua Brasileira de Sinais; Sintaxe de Línguas de Sinais; Marcadores nãomanuais; Movimento de Sobrancelhas

Abstract: This paper aims at discussing the role of eyebrow movement as a marker of
syntactic domains in Brazilian Sign Language (Libras). Based on the analysis of two Libras
narratives, we identified some syntactic constructions marked with eyebrow raising or
lowering. Some of these constructions have already been identified in the literature for other
sign languages and also for Libras, as follows: topicalization, conditionals, relative clauses
and interrogatives - wh-questions and yes/no questions. Additionally, we also identified some
occurrences of eyebrow raising with indexical pointing (determiner-like and pronominal-
like), with adverbial clauses and also with appositions. Keywords: Brazilian Sign Language; Sign Language Syntax; Nonmanual Markers; Eyebrow Movement 


\section{INTRODUÇÃO}

O fato de as línguas de sinais serem línguas em uma modalidade diferente das línguas orais traz corolários interessantes para os estudos gramaticais dessas línguas e também da faculdade de linguagem humana de maneira geral. Assim, um problema que frequentemente se coloca nos estudos gramaticais é como a modalidade visual-gestual das línguas sinalizadas afeta a estrutura linguística.

Um dos principais efeitos de modalidade reside justamente na forma de produçãocompreensão do sinal linguístico e diz respeito aos conceitos de simultaneidade e linearidade. Uma vez que as línguas de sinais possuem dois grandes articuladores principais, as duas mãos, e também faz uso gramatical e sistemático de expressões corporais e faciais, a língua faz um uso muito mais intenso de estruturas simultâneas do que as línguas orais. Isso é justamente o que nos aponta Wilbur:

Línguas orais possuem mais dispositivos segmentais/sequenciais disponíveis, enquanto que dispositivos em layering são menos frequentes. Línguas de sinais são mais propícias a fazer uso de dispositivos simultâneos/layering, mas que dispositivos são esses e quais suas respectivas funções pode variar de uma língua para outra (WILBUR, 2003, p. 343, tradução nossa).

Percebe-se, portanto, que, no caso das línguas orais, produzidas por um único articulador principal - a boca -, a produção linguística é de base sonora e linear/sequencial. Assim, a palavra 'casa' em português, por exemplo, é composta pelos fonemas $/ \mathrm{k} / \mathrm{a} / \mathrm{/z} / \mathrm{a} /$, dispostos sequencialmente no fluxo temporal de emissão linguística. Já no caso das línguas de sinais, produzidas por dois articuladores principais, as mãos, além de articuladores secundários, as expressões faciais e corporais, a produção linguística é de base visual e simultânea. Dessa maneira, no sinal de CASA em Libras, por exemplo, é realizados por diferentes unidades fonológicas (tais como a forma da mão, o espaço em que o sinal é realizado e o movimento do sinal) emitidas simultaneamente no fluxo temporal. É por esse motivo que é comum se afirmar que uma das propriedades centrais das línguas de sinais é simultaneidade na organização do signo linguístico ${ }^{1}$. A representação a seguir compara a realização linear e sequencial das unidades mínimas nas línguas orais com a realização simultânea das unidades mínimas nas línguas sinalizadas:

Figura 1. À esquerda, representação linear das unidades mínimas das línguas orais e, à direita, representação simultânea dos parâmetros das línguas de sinais. $\mu=$ morfema.

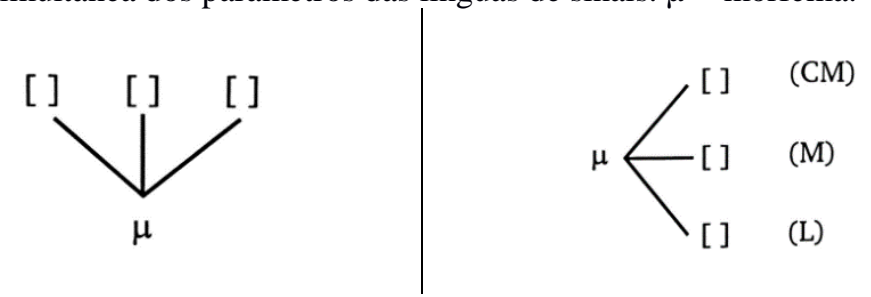

Fonte: QUADROS; KARNOPP, 2004, p. 49.

Além da produção manual, as línguas de sinais também fazem uso linguístico das expressões faciais e corporais, chamadas de expressões não-manuais (ENMs). É importante destacar que as ENMs verdadeiramente linguísticas são as chamadas ENMs gramaticais, que se diferenciam das ENMs afetivas:

\footnotetext{
${ }^{1}$ Para uma análise de layering em Libras e também na estrutura interna do verbo, ver Lourenço (2018) e Lourenço e Wilbur (2018).
} 


\begin{abstract}
Marcadores não-manuais linguisticamente relevantes devem ser distinguidos dos marcadores puramente afetivos, como expressões faciais ou movimentos de cabeça que expressam desgosto, descrença ou surpresa, que são usados por sinalizadores bem como por falantes. A diferença entre os dois tipos de marcadores nem sempre é clara, mas alguns critérios têm sido propostos (PFAU; QUER, 2010, p. 381, tradução nossa).
\end{abstract}

Considerando-se que as ENMs possuem função gramatical nas línguas sinalizadas, o presente trabalho objetiva investigar o papel dos movimentos de sobrancelha (levantamento e abaixamento) na Libras. Mais especificamente, interessa-nos identificar em quais contextos sintáticos esse marcador ocorre e seu escopo (onset, espraiamento e offset).

\title{
1. AS EXPRESSÕES NÃO-MANUAIS NAS LÍNGUAS DE SINAIS E O LAYERING DE INFORMAÇÕES VISUAIS
}

As ENMs gramaticais constituem um importante componente das línguas de sinais, tanto em nível lexical, quanto em nível supra-lexical. Ao permitirem a transmissão de informações linguísticas diferentes em cada nível de articulação (manual x não-manual), as línguas de sinais acabam por fazer uso de maneira bastante produtiva de layering em sua estrutura. Wilbur define layering como "o mecanismo de organização linguística pelo qual múltiplas informações podem ser enviadas simultaneamente. Ele requer que a articulação de cada informação não interfira com a articulação das demais" (WILBUR, 2003, p. 334, tradução nossa).

Assim, pode-se identificar pelo menos quatro principais grandes blocos de informação sendo transmitidos simultaneamente:

i. $\quad$ O sinal manual indica o item lexical;

ii. $\quad$ O espaço de sinalização (o local em que o sinal é localizado no espaço), pode trazer informações relacionadas a noções de referencialidade;

iii. Expressões faciais na parte superior do rosto, que transmitem informações sintáticas;

iv. Expressões faciais na parte inferior do rosto, com função modificadora em nível lexical. 
Figura 2: Layering de informações visuais na Libras. 1) sinal manual; 2) espaço de sinalização; 3) ENMs da face superior; e 4) ENMs da face inferior.

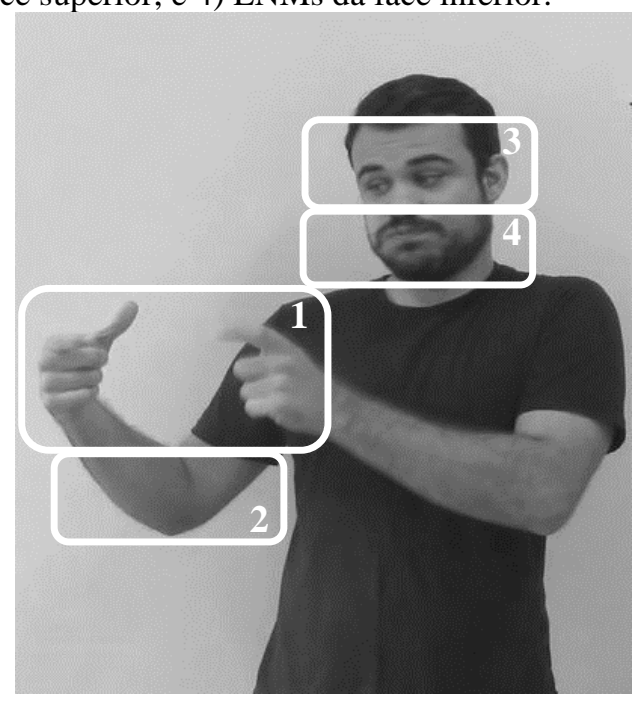

Fonte: Os autores

Interessa-nos, em especial, as ENMs localizadas na face, também chamadas de expressões faciais. A seguir, apresentamos um mapeamento dos diferentes articuladores da face:

Figura 3: Mapeamento das expressões faciais, adaptado e simplificado de Wilbur (2003, p. 338).

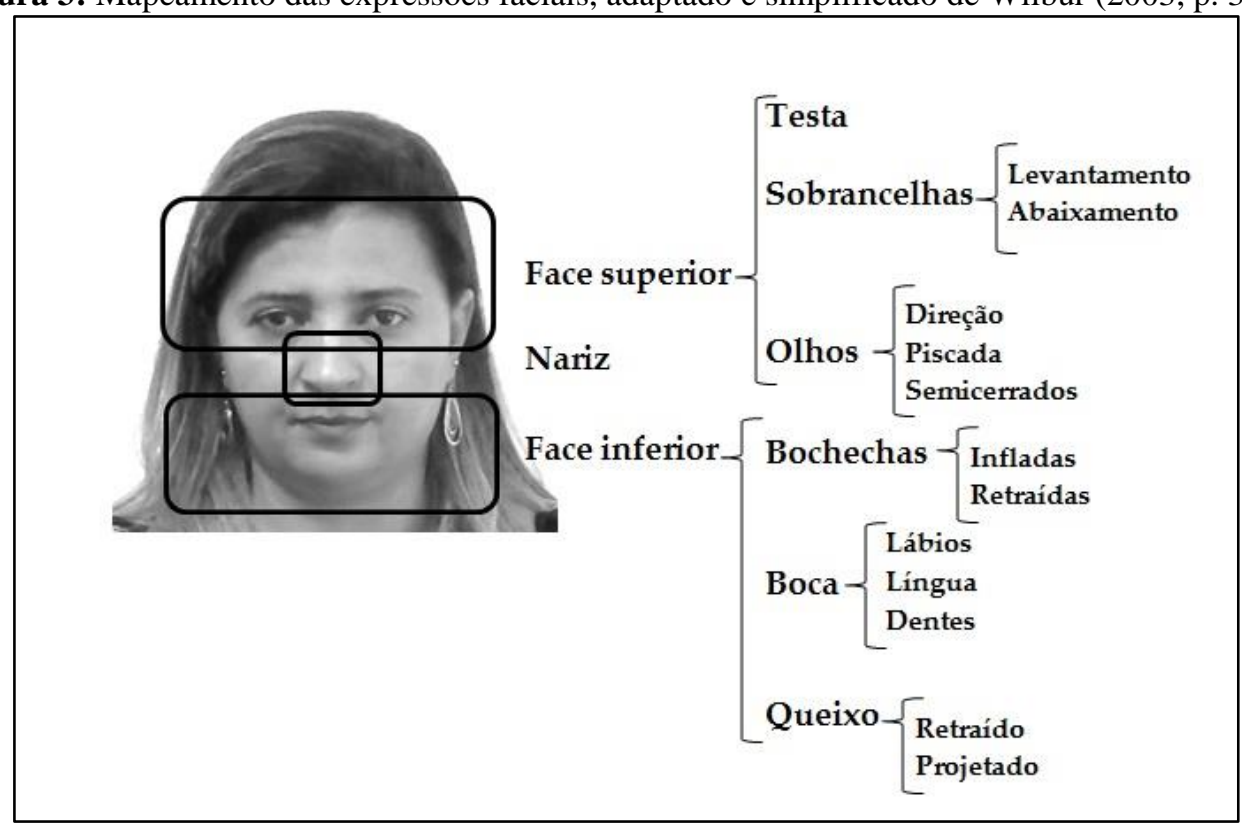

Fonte: Os autores

As expressões faciais podem ser classificadas a partir do nível de representação linguística a qual elas se aderem. De modo que é possível identificarmos expressões faciais lexicais, morfológicas e sintáticas. ${ }^{2}$

As expressões faciais lexicais, também chamadas de fonológicas são parte integrante do item lexical, fazendo parte de sua especificação fonológica. Essas expressões se manifestam de três formas, a saber: i) movimentos do corpo e da cabeça; ii) expressões

\footnotetext{
${ }^{2}$ Essa classificação diz respeito às ENMs de maneira geral. Neste trabalho, focaremos apenas nas expressões faciais, desconsiderando-se movimentos de cabeça e de tronco. Além disso, há também as ENM prosódicas, que também fogem ao escopo de nossa investigação.
} 
faciais; e iii) nos gestos de boca e mouthings (PFAU; QUER, 2010). O sinal de CHEIO, em Libras, é um exemplo de item que é lexicalmente especificado em termos de expressão facial:

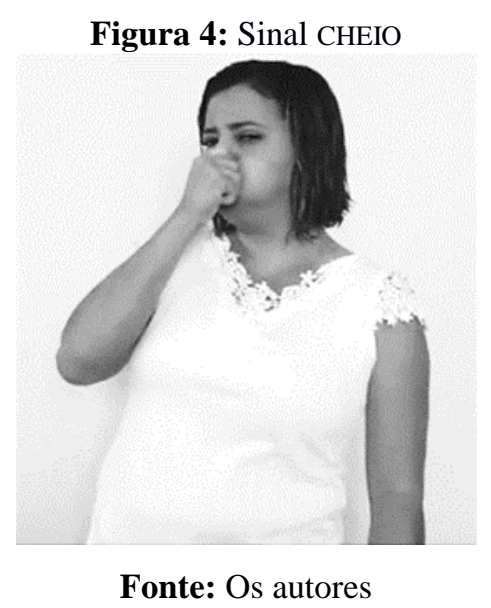

Os gestos de boca são movimentos realizados pela boca, especificados na representação lexical do sinal e que apresentam um padrão que pode mudar durante a articulação, ou se manter constante. Na Libras, ELETRICIDADE seria um exemplo, em que os lábios protusos fazem um movimento de lábios constante, junto com o sinal manual que também apresenta movimento constante.

Figura 5: Sinal ELETRICIDADE

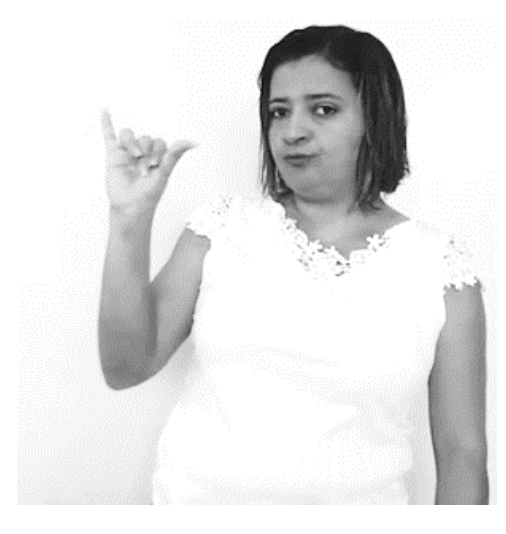

Fonte: Os autores

Segundo Pfau e Quer (2010, p. 3), o mouthing, por sua vez, é "uma articulação silenciosa de (uma parte de) uma palavra da língua oral predominante", junto à sinalização. É um empréstimo da língua oral. Na Libras, o sinal de NUNCA, por exemplo, é acompanhado da representação da língua oral, no mouthing. 
Figura 6. Sinal NUNCA
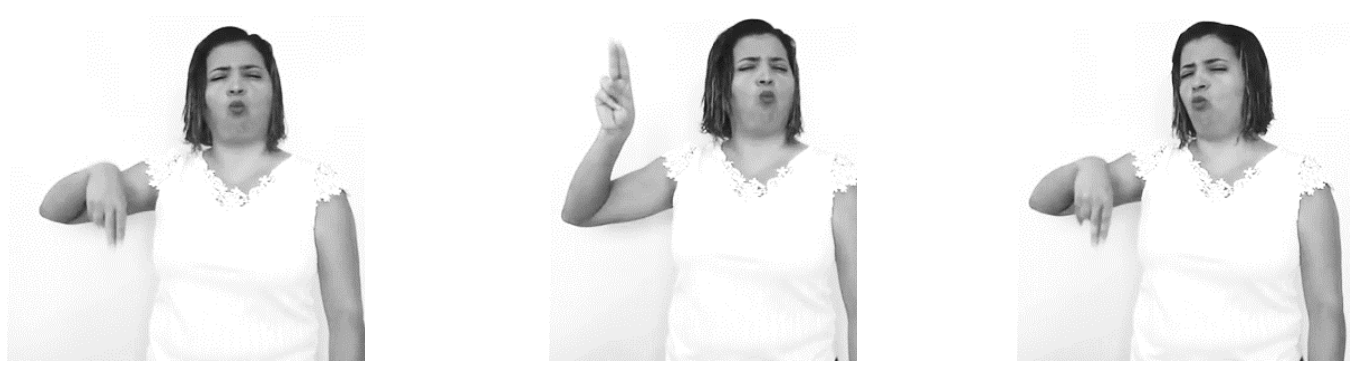

Fonte: Os autores

Já as ENMs morfológicas atuam como modificadores, podendo modificar nomes, adjetivos e verbos, trazendo informações de grau e intensidade.

1) a. JOÃO TRABALHAR ONTEM

'João trabalhou ontem'

b. JOÃO TRABALHAR ++ ONTEM

'João trabalhou muito ontem'

No exemplo anterior, temos a ENM articulada juntamente com o verbo 'TRABALHAR', o que tem como efeito a intensificação dessa ação. As imagens abaixo evidenciam as diferenças:

Figura 7: Sinal TRABALHAR (à esquerda) e TRABALHAR MUITO (à direita).
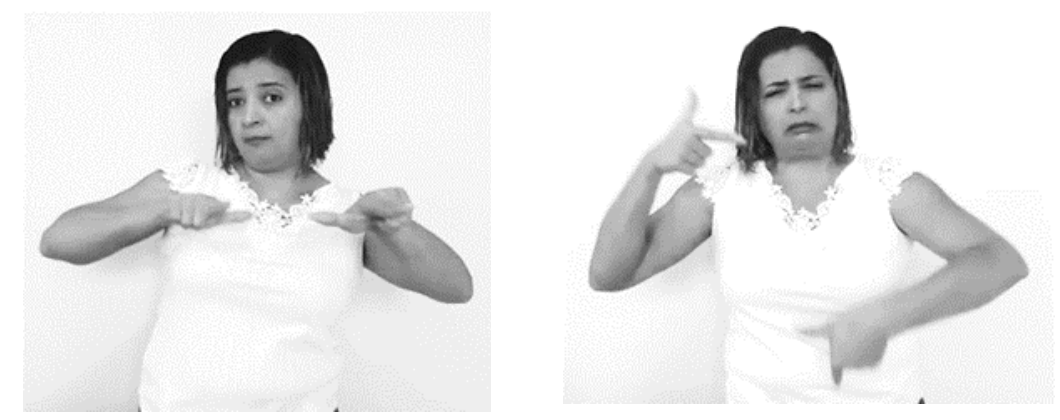

Fonte: Os autores

Percebe-se, então, que a boca é um articulador importante nesse processo, já que os marcadores morfológicos são articulados na parte inferior do rosto (nariz para baixo), o que inclui, além da boca, a bochecha e o queixo (WILBUR, 2003). Para representar o diminutivo, por exemplo, junto com a sinalização manual, o sujeito configura a boca em lábios protusos. Em contrapartida, para expressar o aumentativo, as bochechas inflam. Nos advérbios, a intensidade também é indicada pela boca.

O exemplo abaixo, retirado de Quadros (2011), evidencia isso. A mulher está sinalizando com as mãos o sinal referente a CASA, porém a ENM, articulada pela boca, muda o "tamanho" dessa casa. Além da articulação da boca, há também a articulação do corpo, que contribui para a expressão de intensidade do sinal. Observe: 


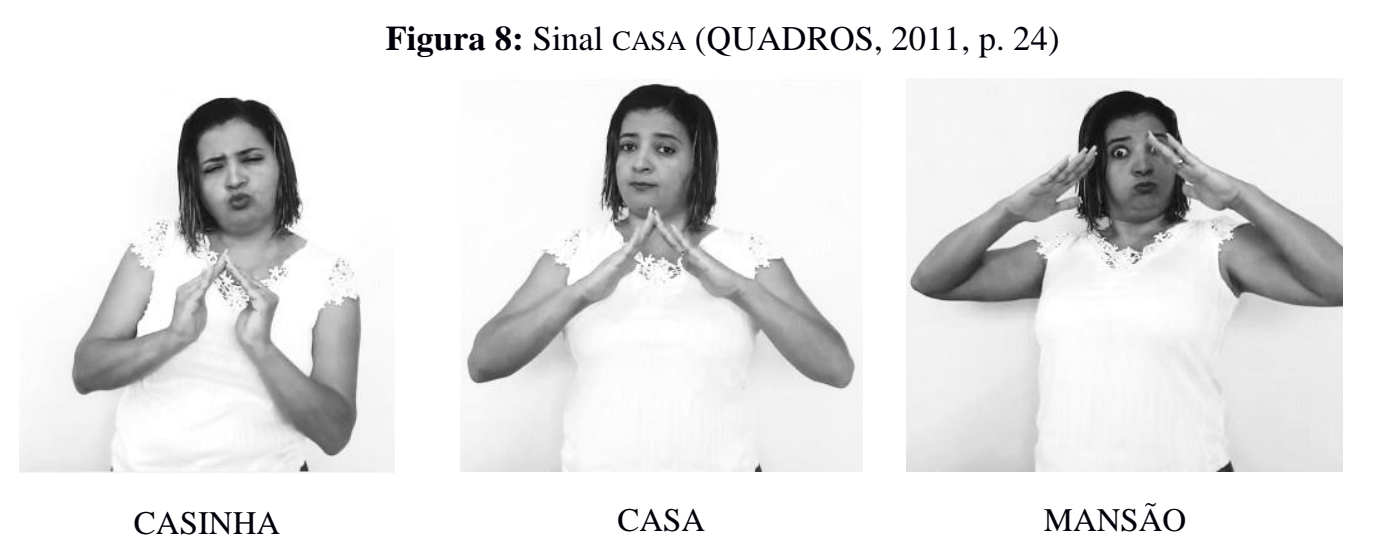

Fonte: imagens dos autores. Adaptado de Quadros (2011, p. 24)

Por fim, têm-se as ENMs sintáticas, cujos articuladores estão localizados na face superior, em oposição às expressões faciais morfológicas (WILBUR, 2003). Neste caso, os marcadores são encontrados em diferentes contextos, podendo demarcar diferentes domínios sintáticos nas línguas de sinais. É justamente um desses marcadores, o movimento de sobrancelhas, que constitui nosso objeto de análise.

\section{O MOVIMENTO DE SOBRANCELHAS ENQUANTO MARCADOR SINTÁTICO}

Dentre as ENMs sintáticas, este artigo destaca o uso das sobrancelhas. É importante ressaltar, como já foi demonstrado, que análises sintáticas em línguas de sinais devem sempre levar em consideração os componentes não-manuais dessas línguas. No caso das sobrancelhas, identificamos, atualmente na literatura, a ocorrência dessa marcação nãomanual em, pelo menos, quatro construções distintas. São elas: tópico, pergunta, condicional e relativas.

A topicalização é um recurso utilizado para que haja uma demarcação da estrutura em tópico, que se diferencia do resto da sentença, que diz algo a respeito do tópico. Ou seja, temos o tópico - item evidenciado dentro da sentença - seguido de um comentário a respeito dele.

Essa estrutura não é exclusiva das línguas de sinais, já que nas línguas orais também topicalizamos frases, como o exemplo do português em (2). Neste caso, o tópico a respeito do qual se faz um comentário é "Esse livro" e o comentário é que "(eu) já li ele". Essa topicalização ocorre a partir do deslocamento dos termos na frase, que na ordem direta seria "Eu já li esse livro", além de haver uma marcação prosódica distinta que indica a topicalização do objeto "esse livro".

2) "Esse livro, (eu) já li ele".

A diferença é que, nas línguas de sinais, além da reformulação da ordem da frase, temos a marcação não-manual, seguida de uma pequena pausa. A respeito dos tópicos em línguas de sinais, Pfau e Quer (2010, p.1) declaram: 
Aarons (1994) diferenciou dois tipos de tópicos a partir de seus estudos da ASL (Língua de Sinais Americana) - os tópicos de movimento e os tópicos gerados na base. A diferença básica entre eles está no fato de que no primeiro grupo o tópico mantém uma relação sintática com o verbo enquanto no segundo, a relação é semântica.
3) a. $\overline{\mathrm{IX}_{\mathrm{A}} \text { MULHER }}$ IX 1 AJUDAR
'Essa mulher, eu ajudei'
ls
b. FUTEBOL IX 1 CRUZEIRO
'No futebol, eu sou Cruzeiro'
[LIBRAS]

Os exemplos apresentados acima ilustram a diferença entre os dois tipos de tópico. Em (3a), o tópico mantém uma relação sintática com o verbo, pois ele o complementa. Neste caso o argumento é deslocado para a periferia esquerda da sentença, ocupando um lugar de maior ênfase na frase. Já no caso de (3b), o tópico já é introduzido na periferia esquerda da sentença, por isso é denominado 'gerado na base', e em seguida, o comentário a respeito dele é feito, estabelecendo-se, então, uma relação semântica entre tópico e comentário, não havendo, assim, movimento de constituinte.

Pfau e Quer (2010, p. 8-9) trazem as conclusões de Aarons a respeito dos tópicos em ASL:

\begin{abstract}
Já foi defendido para a ASL que diferentes tipos de tópicos são acompanhados por marcadores não-manuais levemente diferentes, como olhos arregalados, movimento da cabeça para trás, boca aberta, cabeça balançando para cima e para baixo. Entretanto, para LSC (e outras línguas de sinais) essas diferenças sutis ainda não foram identificadas. (tradução nossa).
\end{abstract}

Esse é o caso da Libras, que apresenta ambos os tipos de tópicos, porém sem uma diferenciação oficialmente reconhecida de outras ENMs associadas ao levantamento das sobrancelhas, como marcas distintivas entre diferentes tipos de tópicos.

A formulação de perguntas nas línguas de sinais também utiliza as sobrancelhas como marcadores sintáticos. Elas são usadas de formas distintas para marcar tipos diferentes de perguntas. Segundo Pfau e Quer (2010, p. 7), normalmente as sobrancelhas estão levantadas para perguntas do tipo Sim/Não (S/N), enquanto as perguntas do tipo QU- são acompanhadas de sobrancelhas abaixadas (testa franzida).

No caso das perguntas, muitas vezes o marcador não-manual é o que vai definir que se trata de uma interrogação, e não uma declaração, isso porque não ocorre mudança na ordem canônica da sentença para a formulação de questões. Conforme afirmam Pfau e Quer (2010, p. 389):

\footnotetext{
$\mathrm{Na}$ verdade, na maioria das línguas de sinais a ENM é a única indicação de que estamos lidando com uma pergunta, já que a ordem das palavras não muda. Além do marcador não-manual, algumas línguas de sinais empregam partículas [manuais] opcionais para perguntas. (tradução nossa)
}

No caso da Libras, a marcação das perguntas é feita majoritariamente pelas ENMs. No caso de perguntas $\mathrm{S} / \mathrm{N}$, a marcação se dá apenas com a articulação não-manual, "há um leve abaixamento da cabeça, acompanhado de elevação das sobrancelhas" (QUADROS, 2011, p. 29). Contudo, essa não é uma regra para todas as línguas de sinais. A NGT (Língua de Sinais Holandesa), por exemplo, é diferente. Pfau e Quer trazem um exemplo em que a 
partícula manual para a marcação da pergunta é a palma da mão virada para cima, que pode aparecer no final da sentença: ls

4) a. ONTEM IX 2 BICICLETA COMPRAR PALMA-PARA-CIMA

'Você comprou a bicicleta ontem?

ls

b. ONTEM IX 2 BICICLETA COMPRAR

'Você comprou a bicicleta ontem?

[Exemplos da NGT (PFAU; QUER, 2010, p. 7) tradução nossa]

Já no caso das perguntas QU-, Quadros descreve a marcação das ENMs como "uma pequena elevação da cabeça, acompanhada do franzir da testa", não relacionando esta última necessariamente ao abaixamento de sobrancelha (QUADROS, 2011, p. 29). Contudo, uma vez que franzir a testa consiste em abaixar as sobrancelhas, incluiremos as interrogativas QUem nossa análise.

As sentenças estruturadas em forma de condicionais, nas línguas de sinais, também possuem a marcação não-manual articulada pelas sobrancelhas. Essa marcação pode envolver outras articulações, como a inclinação do queixo ou aceno de cabeça (PFAU \& QUER, 2010, p.9).

Na Libras, a marcação se dá com o levantamento da sobrancelha na oração condicional, geralmente no início da sentença, que em sua continuação apresenta a oração principal sem a ENM, com expressão neutra. É importante observar que, segundo Pfau e Quer (2010, p.9), nem sempre a partícula condicional da língua, o sinal SI em Libras, estará presente na formulação da sentença, entretanto, a ENM é determinante para que se demarque a condicional.

Nesse sentido, a Libras se comporta de forma semelhante a outras LS, como Língua Israelita de Sinais (ISL). Segundo Dachkovsky (2008), as condicionais em ISL tem a cláusula condicional com a presença do levantamento de sobrancelha e movimento de cabeça para frente como marcadores, enquanto na oração principal, as ENMs são neutras. Já na DGS (Língua de Sinais Alemã), a condição é marcada também com o levantamento de sobrancelhas e o movimento de cabeça para frente, enquanto a consequência não é neutra, pois apresenta o aceno de cabeça como ENM. (HERRMANN apud DACHKOVSKY et al, 2015, p.1). Observe os exemplos abaixo:

ls

5) a. IF IX 3 INVITE-ME BIRTHDAY-PARTY OF-HIM, IX 1 GO

'Se ele me convidar para a festa de aniversário dele, eu irei'

6) b. TRAIN STRIKE, I HOME STAY

'Se os trens entrarem em greve, eu fico em casa.'

c. TRAIN STRIKE, I HOME STAY

'Os trens entram em greve. Eu fico em casa.'

[DGS (DACHKOVSKY, 2015, p. 2-tradução nossa)] 
As sentenças relativas são aquelas que, introduzidas por um nome, modificam um sintagma nominal e desempenham uma função sintática adjetival. No Português, normalmente, a oração relativa é iniciada por um pronome relativo, como o "que" ("O livro que eu li é muito bom'); as línguas de sinais, entretanto, utilizam-se de ENMs para demarcála.

É claro que entre as línguas de sinais, haverá distinções para essa marcação, apesar de o uso das sobrancelhas como marcadores de orações relativas ser frequente. A LIS (Língua Italiana de Sinais) é um exemplo interessante para esse caso. Segundo Branchini e Donati (2009, p.163) a construção das relativas da LIS ocorre com o uso de um sinal, $\mathrm{PE},{ }^{3}$ que ocorre ao fim da oração relativa, juntamente com a marcação não-manual. A respeito desta, as autoras declaram: "O marcador não-manual glosado como 'rel' consiste no levantamento das sobrancelhas e tensão dos olhos e bochechas. Sua realização e espraiamento alcançam sua máxima intensidade no sinal PE, embora sua expressão possa variar". (BRANCHINI E DONATI, 2009, p. 163, tradução nossa). A construção pode ser observada mais claramente no exemplo em (7) apresentado por elas.

7) a. CACHORRO GATO PERSEGUIR PEi $_{\text {(IX }}$ ) CASA VIR PRONTO

'O cachorro que perseguiu o gato veio para casa'

rel

b. CACHORRO GATO PERSEGUIR PE $_{\mathrm{i}}\left(\mathrm{IX}_{\mathrm{i}}\right)$ CASA VIR PRONTO

'O cachorro que perseguiu o gato veio para casa'

c. * CACHORRO PERSEGUIR GATO CASA VIR PRONTO.

'O cachorro que perseguiu o gato veio para casa'

[LIS (BRANCHINI e DONATI, 2009, p. 163, tradução nossa)]

Apesar de a Libras também utilizar a marcação não-manual, as estruturas são diferentes. Isso se dá pelo fato de a ordem básica das sentenças na LIS ser diferente da ordem básica da Libras, já que a primeira é SOV (Sujeito, Objeto, Verbo), enquanto a segunda é SVO (Sujeito, Verbo, Objeto). Quanto à marcação manual, como o sinal PE, da LIS, na Libras é possível haver uma marcação manual nas orações relativas (o sinal É/SER), marcada juntos com a elevação das sobrancelhas, porém, o foco deste trabalho será apenas a análise sintática da ENM.

Essas quatro ocorrências - tópico, condicional, interrogativa e relativa - são, portanto, os contextos já descritos na literatura em que a sobrancelha é usada como marcador sintático na Libras. É válido ressaltar que há alguns autores que falam em 'abaixamento de sobrancelha', para a Libras, e para outras línguas de sinais. Contudo, o único contexto analisado para essa marcação foi o das interrogativas QU-, totalizando assim cinco ocorrências de análise.

\footnotetext{
${ }^{3}$ A respeito de PE, Branchini e Donati declaram: “A marca PE coocorre com a articulação silenciosa de uma oclusiva labial. PE é realizado manualmente com o dedo indicador esticado e agitado para baixo. Ela ocorre sistematicamente na periferia direita da oração [relativa] (seguindo modais, aspecto e negação, cf. Cecchetto $e t$ al. 2006). PE é correferencial ao NP interno à oração, e essa correferência pode ser realizada por meio da concordância no espaço" (BRANCHINI e DONATI, 2009, p. 163, tradução nossa).
} 


\section{OS CONTEXTOS DE MOVIMENTO DE SOBRANCELHAS NA LIBRAS}

Neste trabalho, partimos da análise de duas narrativas sinalizadas. São elas: "O

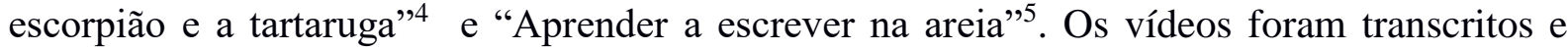
anotados, utilizando-se a ferramenta ELAN ${ }^{6}$. Para tanto, foram criadas as seguintes trilhas no ELAN: i) glosa, ii) sinal, iii) enm_ls (anotadas todas as ocorrências do movimento de sobrancelha), iv) enm_função (anotadas as funções sintáticas das respectivas orações), v) tradução livre.

A partir da transcrição dos dados realizada no ELAN, selecionamos os trechos que continham a marcação não-manual articulada pelas sobrancelhas. Elas estão relacionadas a seguir, divididas pelas seguintes categorias: i) construções de tópico; ii) construções interrogativas do tipo $\mathrm{S} / \mathrm{N}$; iii) construções interrogativas QU-; iv) condicionais; v) construções relativas. Adicionamos uma sexta categoria chamada de "outras ocorrências", de modo a apresentar outras construções identificadas durante a análise dos vídeos que contêm a marcação das sobrancelhas.

Figura 5: Captura de tela do ELAN, mostrando as trilhas utilizadas na análise do vídeo "O escorpião e a

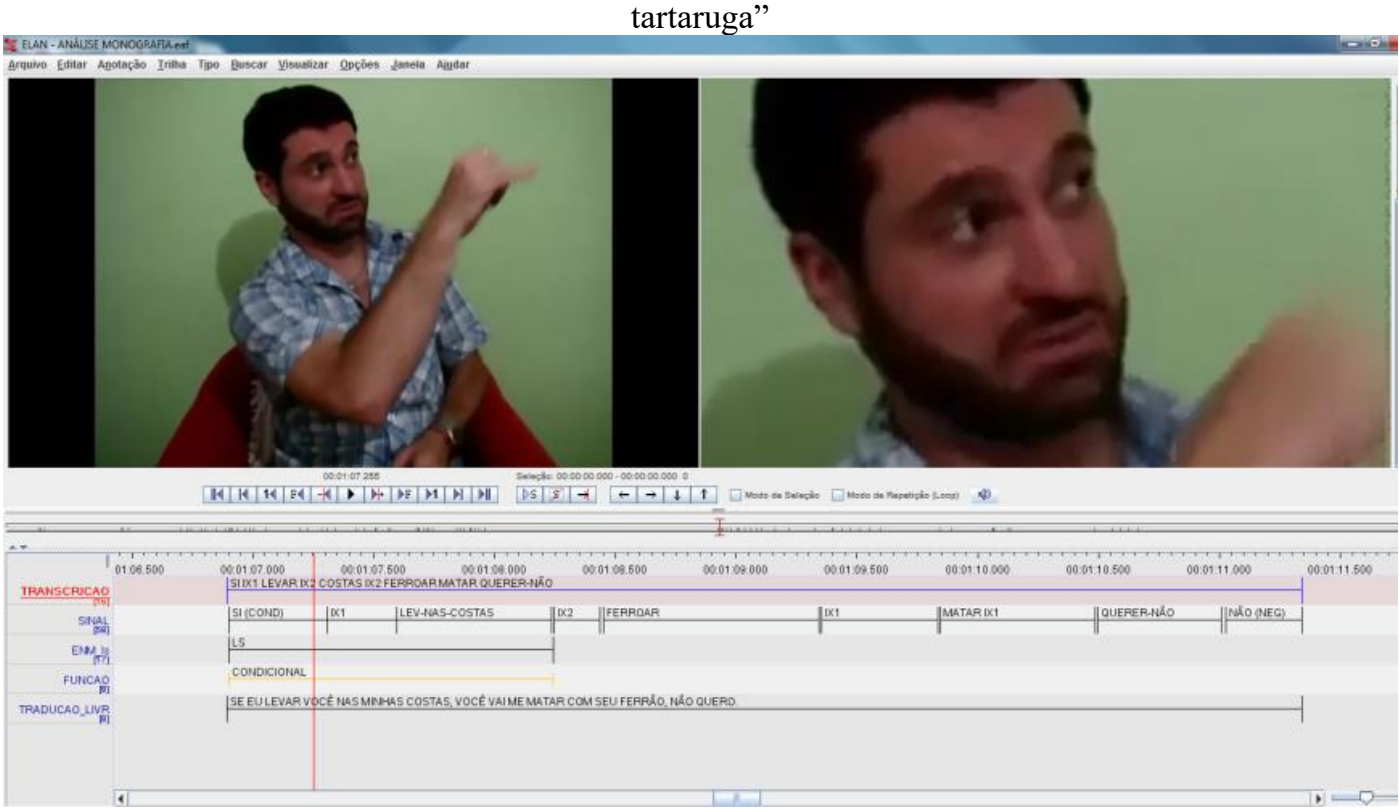

Fonte: Os autores

A seguir, apresentamos as categorias identificadas.

\footnotetext{
${ }^{4}$ Disponível em: https://www.youtube.com/watch?v=qHZDpPps9Zg e utilizado com a permissão do autor Rimar Segala.

${ }^{5}$ Disponível em: http://tvines.org.br/?p=5765\&paged=11 . Os materiais do INES (Instituto Nacional de Educação dos Surdos) são de livre acesso e para uso público. Desse modo, uso em pesquisas, citações e referência estão permitidas, sendo proibido apenas comercialização integral dos produtos. Os produtos podem ser conferidos como livremente disponibilizados em: www.ines.gov.br/publicacoes e www.ines.gov.br/seer.

6 O ELAN é o Eudico Linguistic Annotation, programa desenvolvido pelo Max Planck Institute for Psycholinguistics, Nijmegen, Netherlands. Disponível em: https://tla.mpi.nl/tools/tla-tools/elan/ .
} 


\subsection{A CONSTRUÇÃO DE TÓPICOS ${ }^{7}$}

Conforme já descrito anteriormente, a construção do tópico na Libras ocorre tanto com o tópico de movimento quanto com o tópico gerado na base, e ambos puderam ser comprovados nos vídeos analisados. Além disso, o elemento topicalizado ocorre sempre no início da frase e a marca da sobrancelha é restrita a esse elemento, não se espraiando para o resto da sentença.

No vídeo "O escorpião e a tartaruga" foram identificadas 2 ocorrências de sobrancelha marcando tópico. Apresento a seguir, cada uma dessas ocorrências.

\section{Trecho 1:}

\section{ls}

IX 3 TARTARUGA <RASTEJAR> SOFRER <RASTEJAR>

'A tartaruga rastejava com muita dificuldade.'

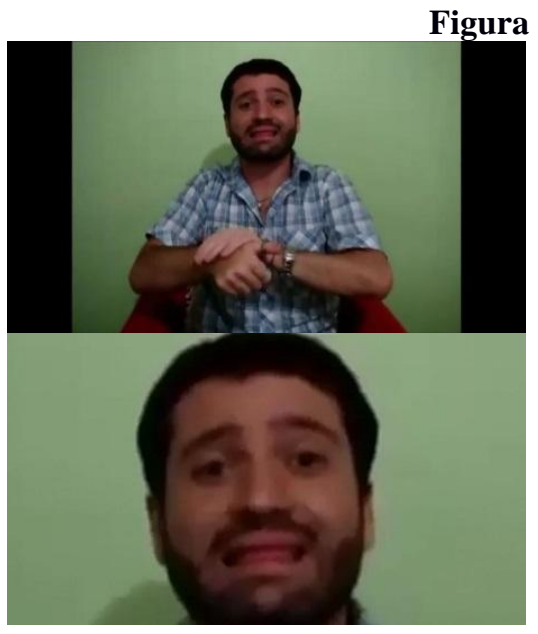

TARTARUGA

Figura 6. Levantamento de sobrancelha no trecho 1.

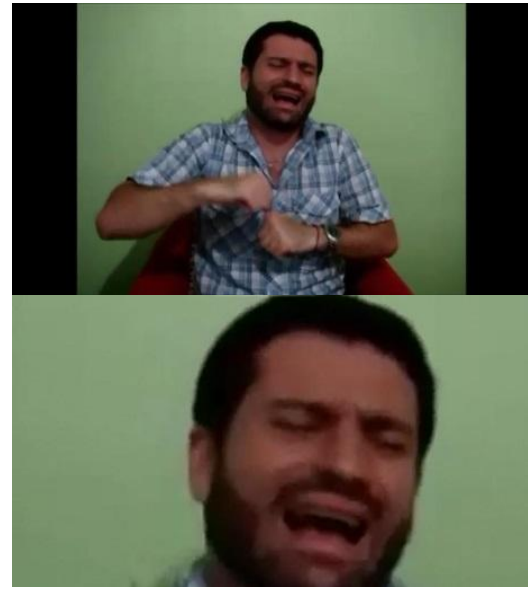

RASTEJAR

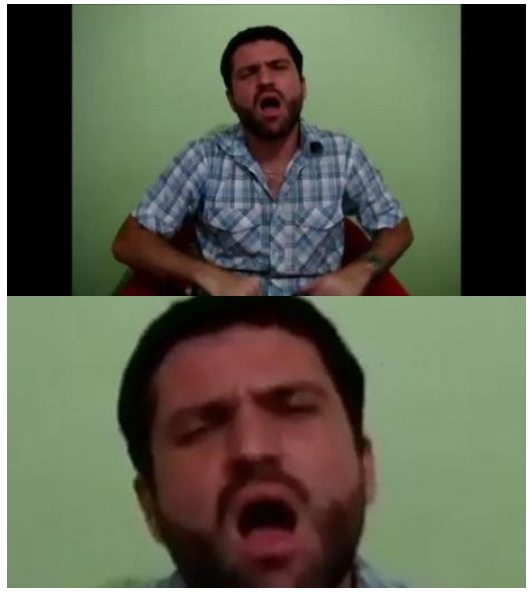

SOFRER

Fonte: elaborado pelos autores.

Imagens retiradas do vídeo "O Escorpião e a tartaruga", de Rimar Segala, com sua permissão

No caso do trecho 1 é possível observar que o tópico construído é um tópico de movimento, o tópico A TARTARUGA também exerce a função sintática de sujeito da oração. Conforme o esperado, o levantamento de sobrancelha é restrito ao elemento topicalizado, não se espraiando para os outros constituintes da sentença.

\section{Trecho 2:}

\section{ls}

ESCORPIÃO NÃO-COMBINA FOGO+

'Escorpião não combina com fogo'.

\footnotetext{
7 Nesta análise, consideramos apenas sintagmas nominais plenos topicalizados. Construções que continham apenas um elemento pronominal, como, por exemplo, uma apontação não foram analisadas. Este recorte é devido ao fato de não termos ainda uma descrição completa dos pronominais da Libras, tampouco das ENMs que os acompanham.
} 
Figura 7. Levantamento de sobrancelha no trecho 2.

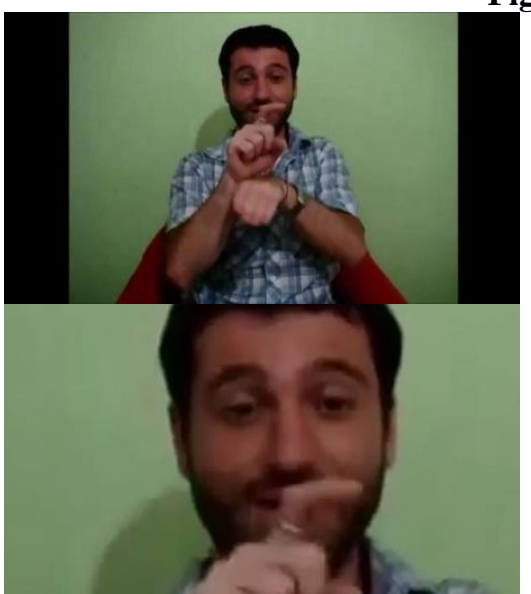

ESCORPIÃO

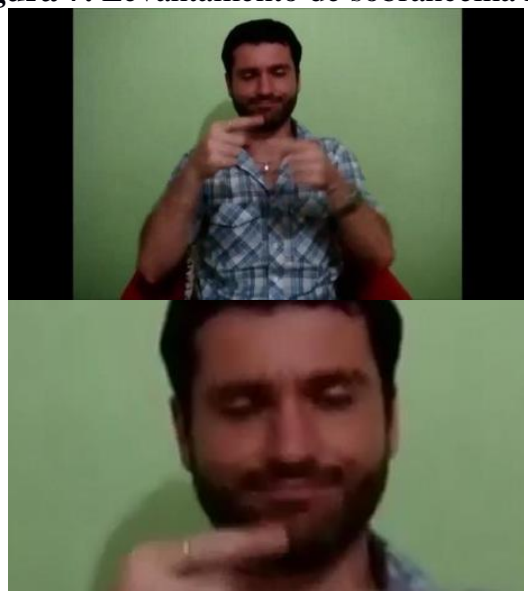

NÃO-COMBINA

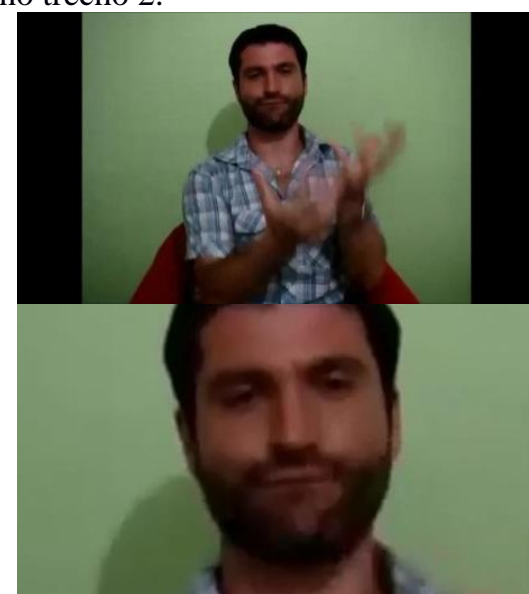

FOGO+

Fonte: elaborado pelos autores. Imagens retiradas do vídeo "O Escorpião e a tartaruga”, de Rimar Segala, com sua permissão

O trecho 2, também é um exemplo de tópico de movimento, já que o sujeito da oração O ESCORPIÃO moveu-se para a posição de tópico. Novamente, percebe-se que a sobrancelha somente permanece levantada na sinalização do sujeito topicalizado.

No vídeo "Aprende a escrever na areia", também identificamos 2 marcações de tópico.

\section{Trecho 3:}

ls

SERVOS ENTRAR-NO-RIO

'Os servos iam entrando no rio.'

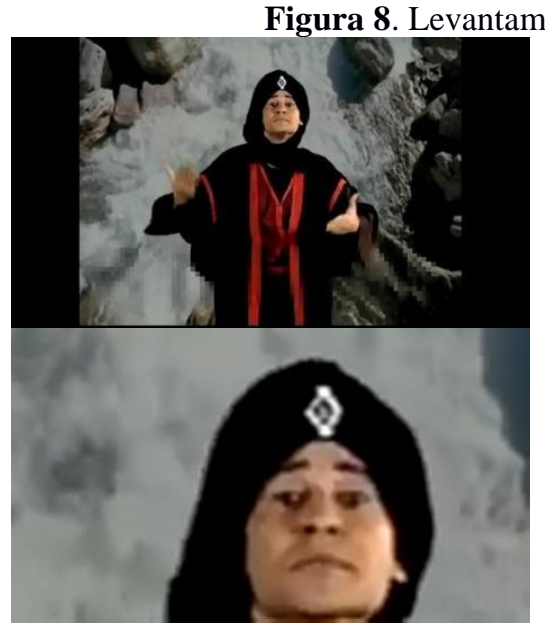

SERVOS

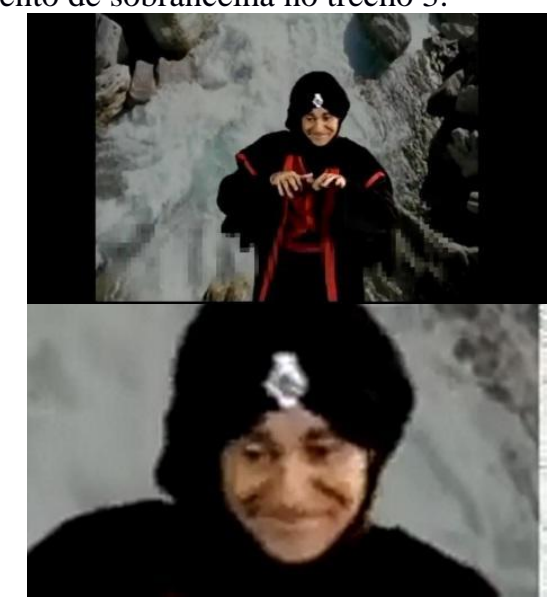

ENTRAR-RIO

Fonte: elaborado pelos autores.

Imagens retiradas do vídeo "Aprende a escrever na areia" (TV INES)

Assim como nos trechos anteriores, tem-se um tópico de movimento em que o sujeito da sentença é topicalizado. 


\section{Trecho 4:}

\section{ls}

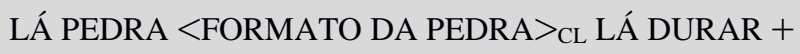

'Lá na pedra, [as coisas] duram eternamente.'

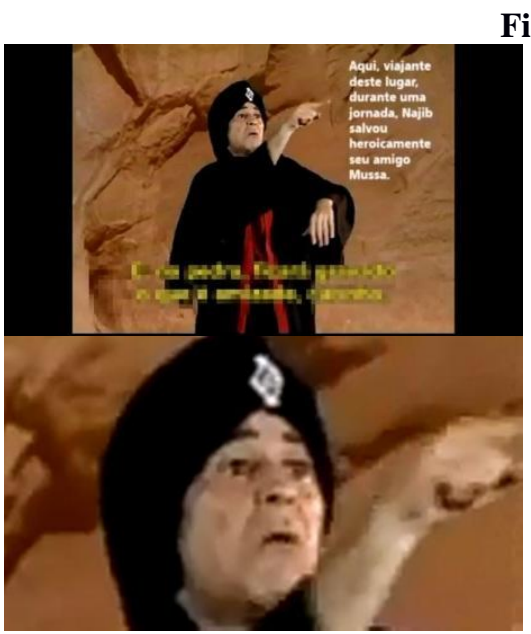

LÁ

Figura 9. Levantamento de sobrancelha no trecho 4.

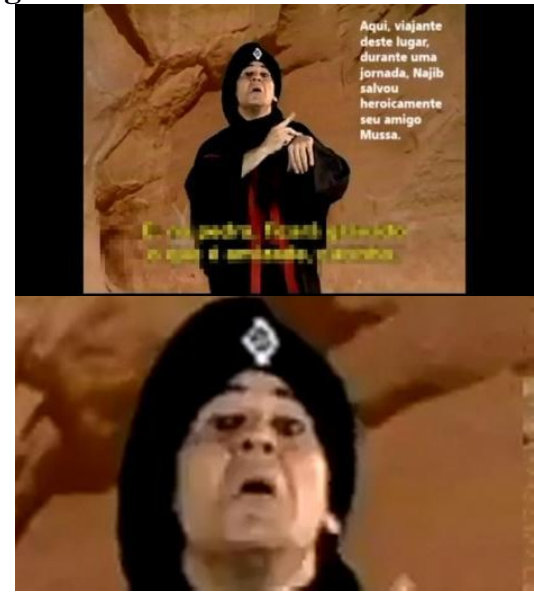

PEDRA

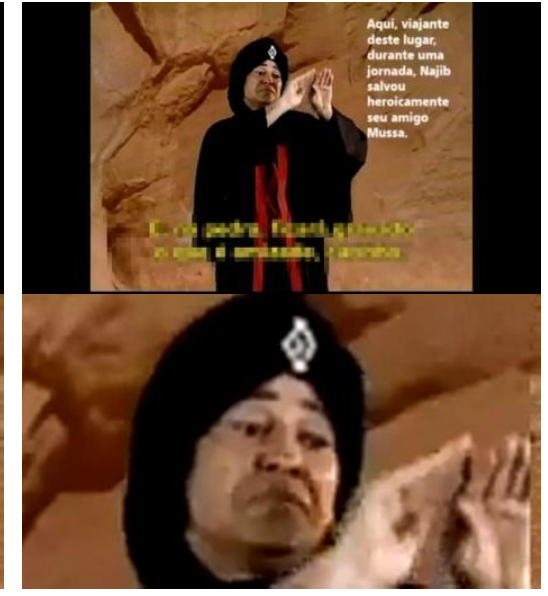

$<$ FORMATO DA PEDRA $\rangle_{\mathrm{CL}}$

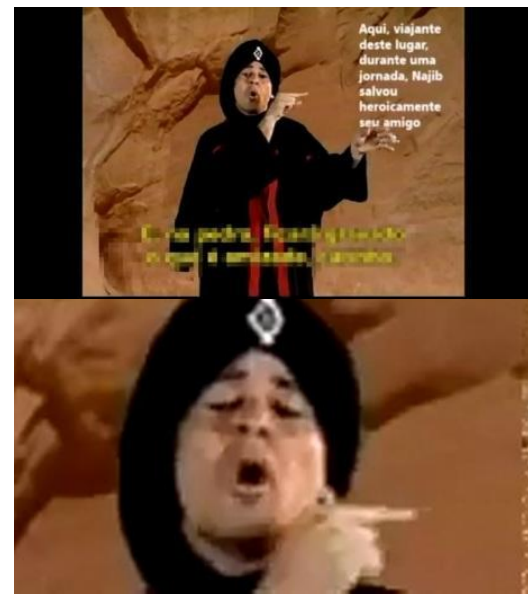

LÁ

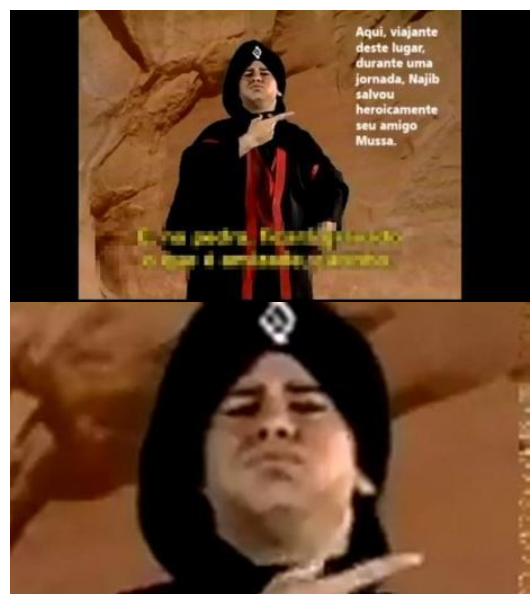

DURAR+

Fonte: elaborado pelos autores.

Imagens retiradas do vídeo "Aprende a escrever na areia" (TV INES)

No trecho 4, observamos uma construção de tópico gerado na base, de modo que a relação entre o tópico e o comentário é apenas semântica, não sendo o elemento topicalizado argumento do verbo da oração matriz. Note novamente que ao término da locução topicalizada, a sobrancelha retorna a sua posição neutra.

\subsection{INTERROGATIVAS DO TIPO S/N}

Quanto à ocorrência de marcação não-manual, articulada pela sobrancelha, na construção de interrogativas do tipo $\mathrm{S} / \mathrm{N}$, foram registradas 1 ocorrência no vídeo "O Escorpião e a Tartaruga" e 1 ocorrência no vídeo "Aprende a escrever na areia". O fato de os vídeos serem narrativas explica a baixa ocorrência desse uso, já que seu uso acaba sendo restringido à contextos de discurso direto. 


\section{Trecho 5:}

Is(interrogativa)

direção do olhar

TARTARUGA CERTO

'A tartaruga [perguntou]: - Tem certeza?'

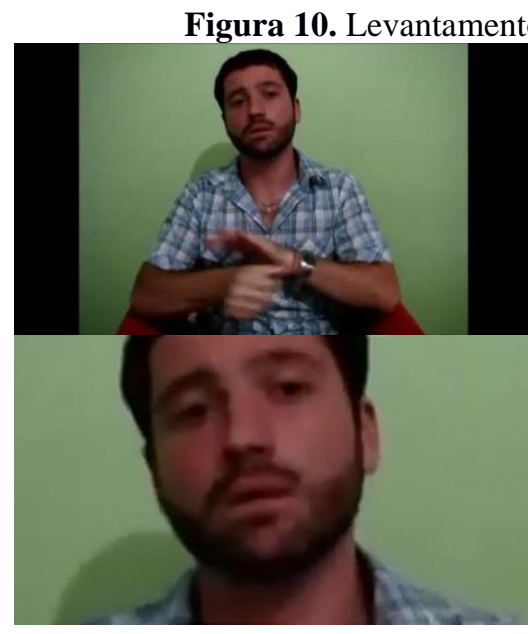

TARTARUGA

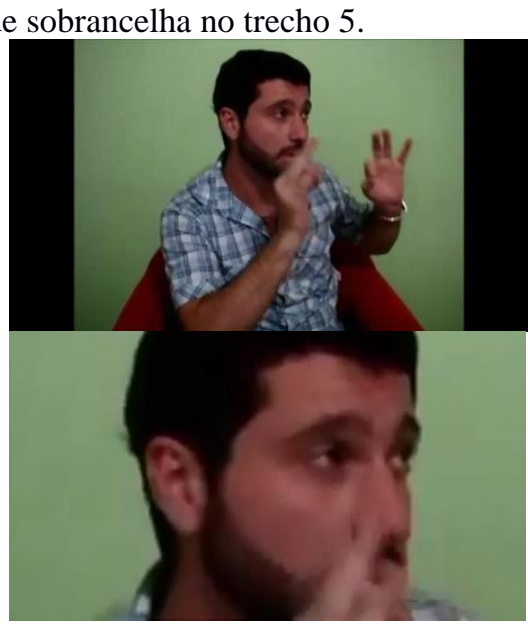

CERTO

Fonte: elaborado pelos autores.

Imagens retiradas do vídeo "O Escorpião e a tartaruga", de Rimar Segala, com sua permissão.

\section{Trecho 6:}

$$
\begin{aligned}
& \text { Is(interrogativa) } \\
& \hline \text { V-I-U } \\
& \text { 'Viu?' }
\end{aligned}
$$

Figura 11. Levantamento de sobrancelha no trecho 6.
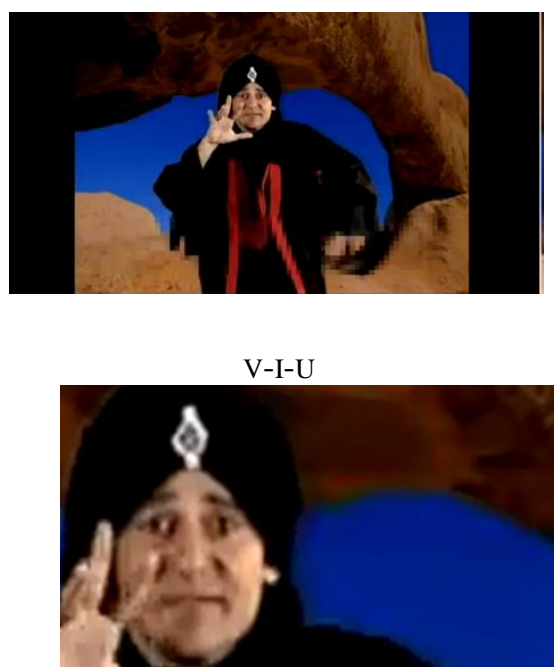

Fonte: elaborado pelos autores.

Imagens retiradas do vídeo "Aprende a escrever na areia" (TV INES)

Em ambos os trechos acima, confirma-se o levantamento da sobrancelha, conforme previsto na literatura. Novamente, chama-se a atenção para o fato de que o escopo da ENM se dá apenas sobre os elementos que compõem a oração interrogativa. No trecho 5 , observa-se que apenas o sinal CERTO é marcado e, no trecho 6, o sinal VIU recebe o levantamento da sobrancelha. 


\subsection{INTERROGATIVAS DO TIPO QU-}

As interrogativas do tipo QU- foram inseridas nessa análise devido à pergunta que surgiu sobre qual seria a diferença entre testa franzida e sobrancelhas abaixadas. Quadros (2011, p. 29) afirma que as interrogativas do tipo QU- são marcadas por "uma pequena elevação da cabeça, acompanhada do franzir da testa". Porém, na literatura, a expressão lowered eyebrows (sobrancelhas abaixadas) frequentemente surgiu para se referir a um tipo de ENM articulada pela sobrancelha e presente nas construções interrogativas do tipo QU-.

Pfau e Quer (2010) são exemplos de autores que usam a nomenclatura 'abaixamento de sobrancelhas' no contexto das interrogativas QU-. Eles declaram: "na maioria das línguas de sinais, interrogativas QU- são acompanhadas do abaixamento de sobrancelhas, frequentemente combinado com um pequeno aceno de cabeça (headtilt)" (PFAU \& QUER, 2010, p.7, tradução nossa). Seguindo, portanto, a descrição dada pelos autores, achamos que seria válido incluir esta nova categoria em minha análise.

Foram registradas 2 ocorrências de interrogativas QU- para o vídeo "O escorpião e a tartaruga" e 1 ocorrência para o vídeo "Escrevendo na areia". Todas elas demonstram de forma clara que a sobrancelha abaixa quando a partícula QU- é sinalizada.

\section{Trecho 7:}

ls(interrogativa)

ACONTECER O-QUE

'O que aconteceu?'

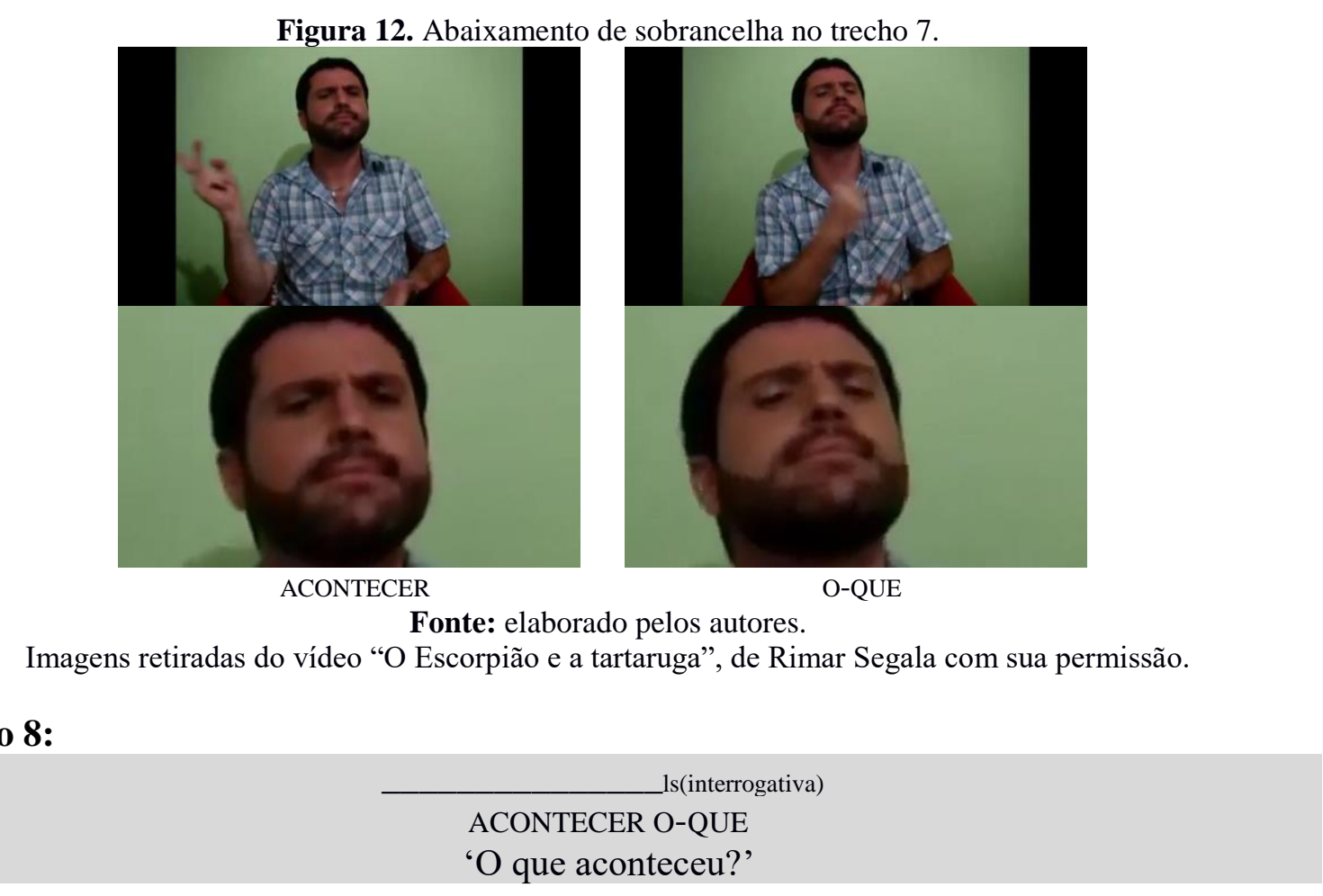


Figura 13. Abaixamento de sobrancelha no trecho 8 .

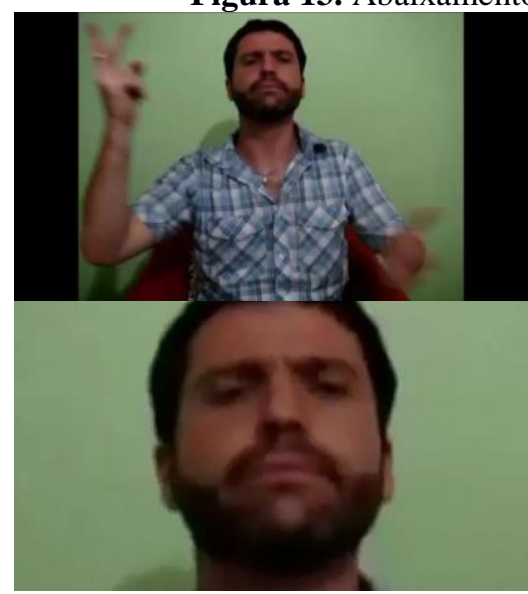

ACONTECER

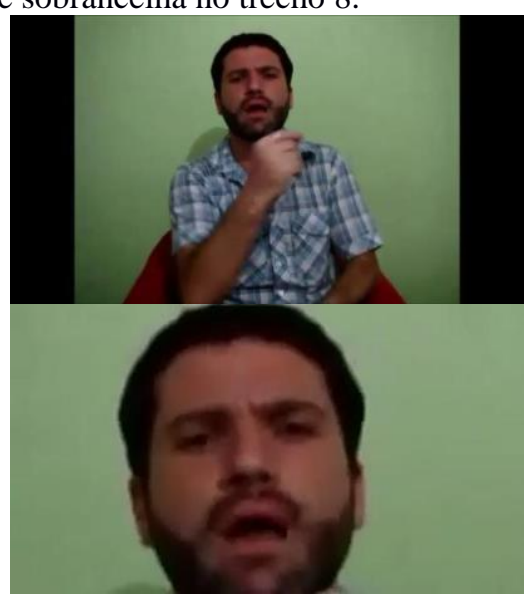

O-QUE

Fonte: elaborado pelos autores.

Imagens retirados do vídeo "O Escorpião e a tartaruga", de Rimar Segala, com sua permissão

\section{Trecho 9:}

O-QUE (interrogativa)
'O que?'

Figura 14. Abaixamento de sobrancelha no trecho 9.
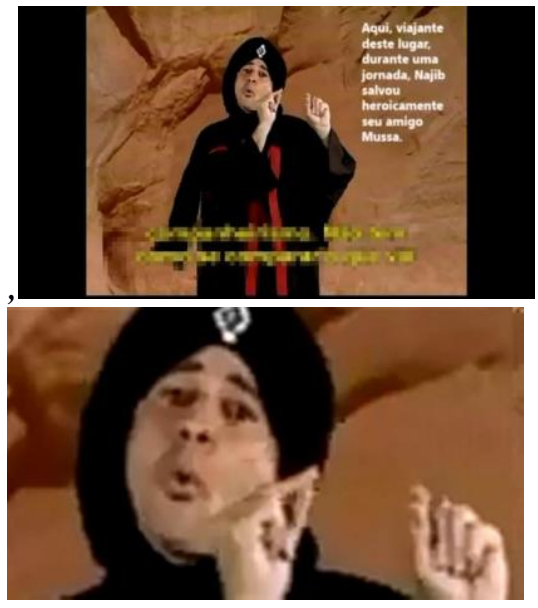

O-QUE

Fonte: elaborado pelos autores.

Imagens retiradas do vídeo "Aprende a escrever na areia" (TV INES).

Identificamos ainda uma outra sentença interrogativa QU- no vídeo “Aprende a escrever na areia". Porém, o narrador estava de lado e, portanto, não foi possível identificar a posição de sua sobrancelha, conforme vemos abaixo: 
Figura 15: Construção QU- não analisada.

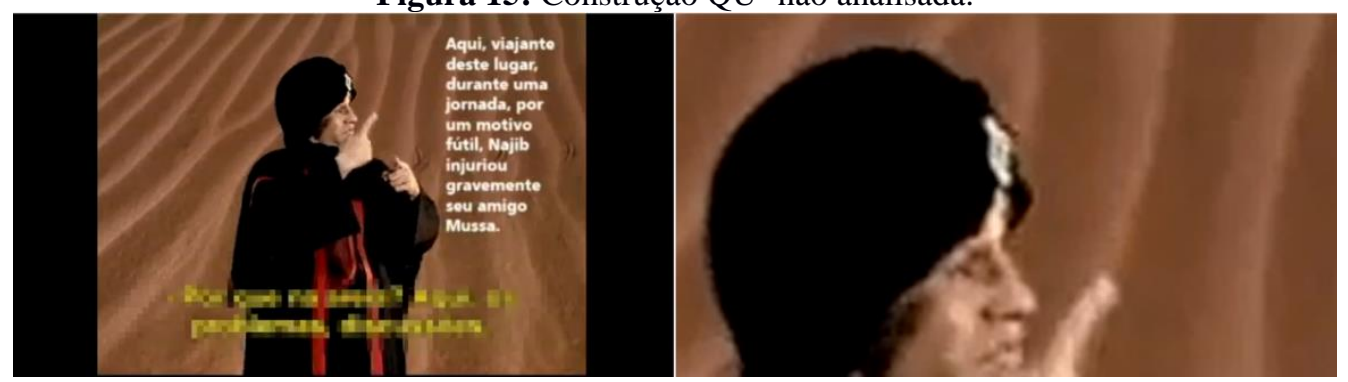

Fonte: elaborado pelos autores.

Imagens retiradas do vídeo "Aprende a escrever na areia" (TV INES).

\subsection{CONDICIONAIS}

Nas condicionais ocorre a elevação da sobrancelha, conforme o descrito na seção 2.4. Nas análises foi possível perceber que a sobrancelha se articula conforme o esperado, ou seja, permanece levantada durante a condição, enquanto que, na consequência, a expressão se torna neutra. O uso da partícula "se" também se mostra opcional, sendo que nos vídeos analisados há os dois tipos de ocorrência.

Para esse tipo de uso, foram observadas 2 ocorrências no vídeo "O escorpião e a tartaruga". Nenhuma ocorrência foi observada no outro vídeo, "Aprende a escrever na areia".

\section{Trecho 10:}

ls(interrogativa)

SI IX 1 <LEVAR-NAS-COSTAS> IX 2 V-A-I FERROAR 1

'Se eu levar você nas minhas costas, você vai me ferroar'

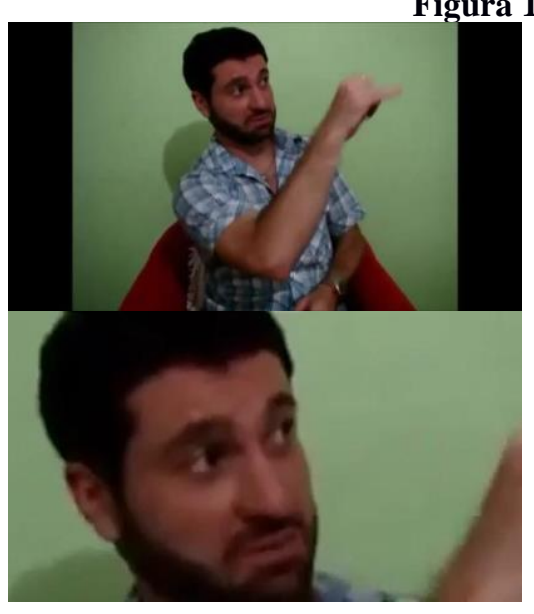

SI

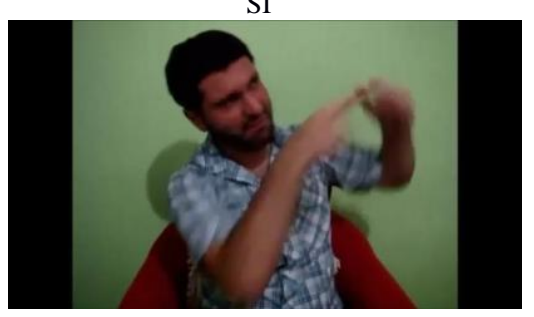

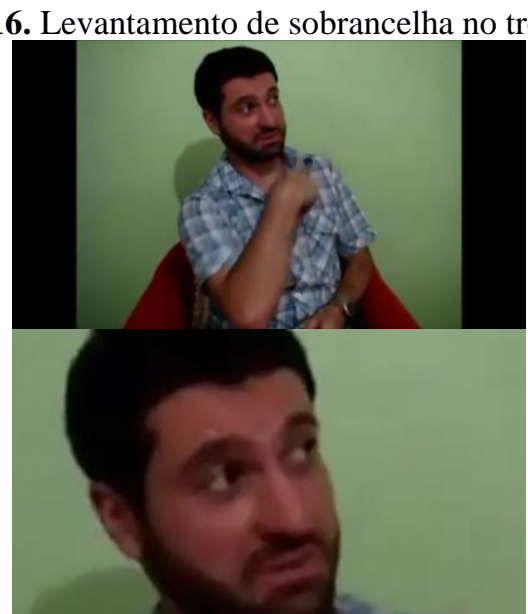

$\mathrm{IX}_{1}$

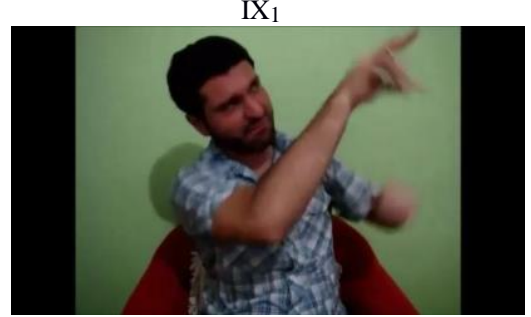

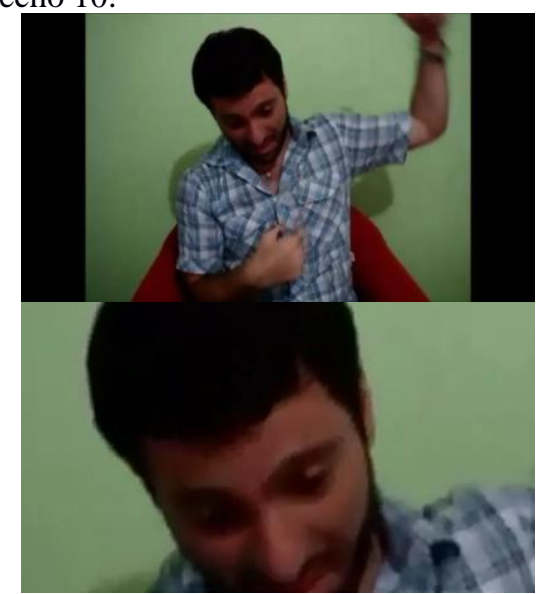

<LEVAR-NAS-COSTAS>

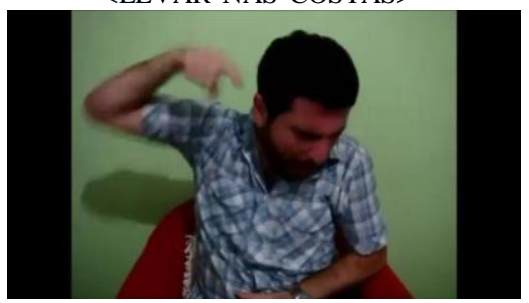




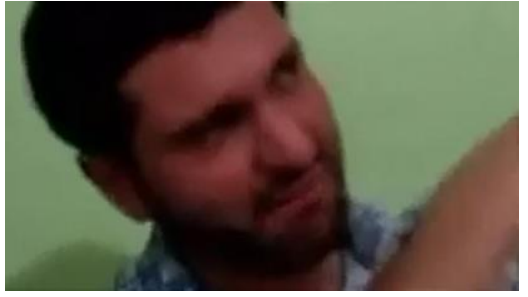

$\mathrm{IX}_{2}$

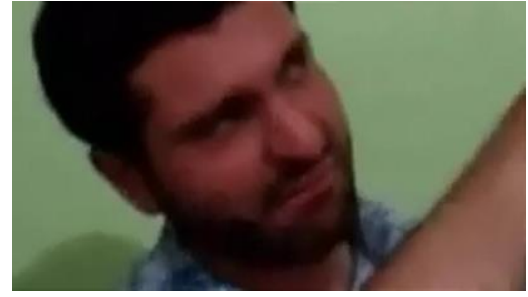

V-A-I

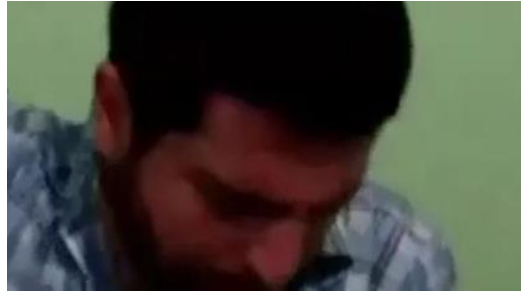

FERROAR $_{1}$

Fonte: elaborado pelos autores.

Imagens retiradas do vídeo "O Escorpião e a tartaruga", de Rimar Segala, com sua permissão.

No trecho 10 observamos que o levantamento de sobrancelha espraia-se apenas sobre a oração que apresenta condição e retorna a sua posição natural na oração matriz. Note que neste trecho a partícula condicional S-I é produzida pelo sinalizador.

\section{Trecho 11:}

$\left.\mathrm{IX}_{1}\langle\text { SUBIR-EM-CIMA }\rangle_{\mathrm{CL}} 2 \mathrm{AJUDAR}_{1}<\mathrm{ATRAVESSAR-RIO}\right\rangle_{\mathrm{CL}}\langle\text { EMBAIXO-DE-MIM }\rangle_{\mathrm{CL}} \mathrm{IX}_{1}$ FERROAR $_{2} \mathrm{~N}$ ÃO.

'(Se) eu subir em cima de você e você me ajudar, atravessamos o rio e eu não vou te picar'.

Figura 17. Levantamento de sobrancelha no trecho 11

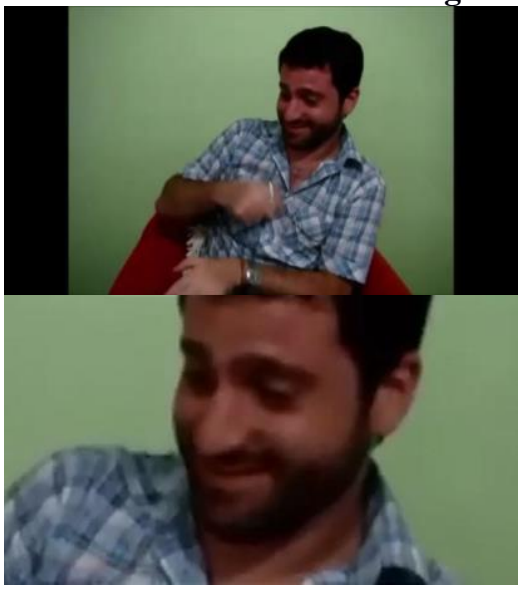

$\mathrm{IX}_{1}$

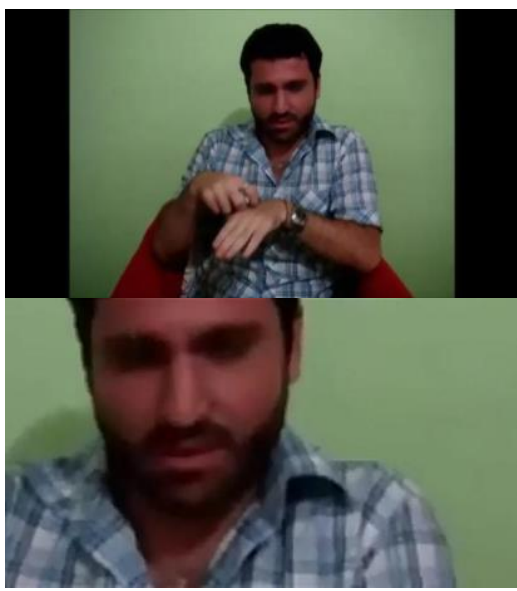

$\langle\text { ATRAVESSAR-RIO }\rangle_{\mathrm{CL}}$

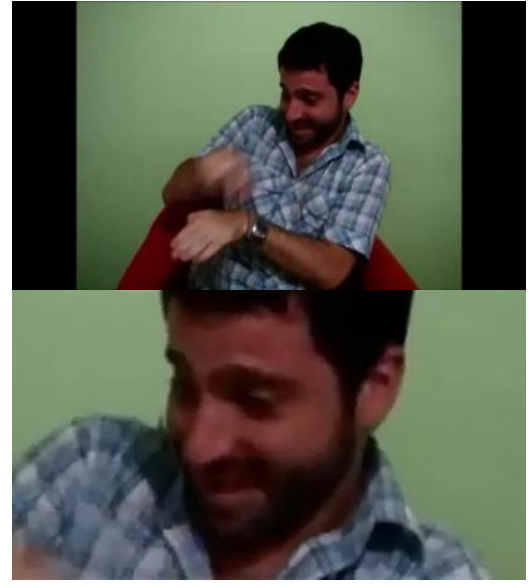

$\langle\text { SUBIR-EM-CIMA }\rangle_{\mathrm{CL}}$

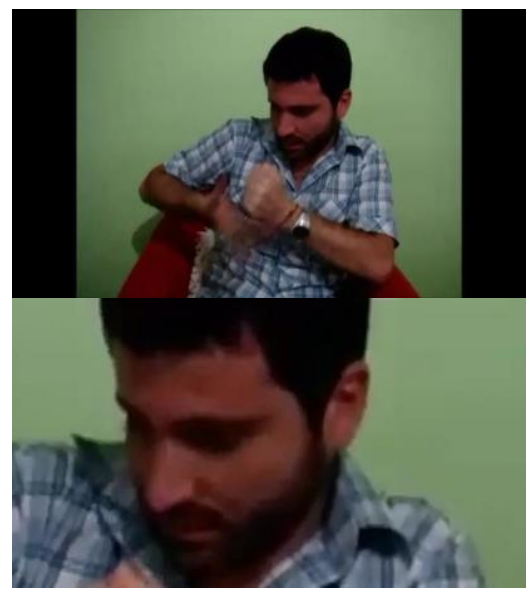

$\langle\text { EMBAIXO-DE-MIM }\rangle_{\mathrm{CL}}$

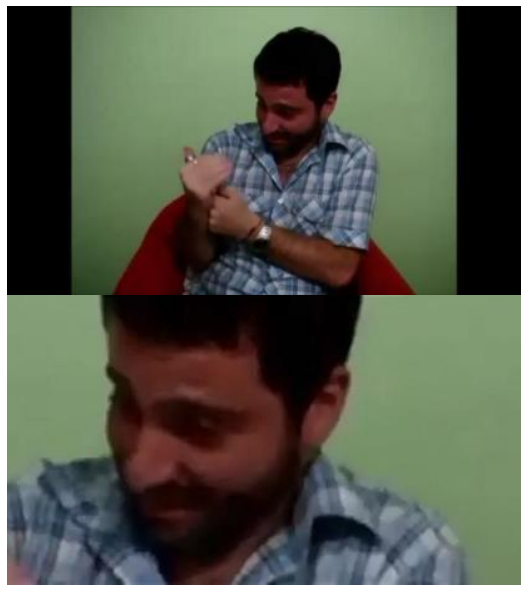

${ }_{2} \mathrm{AJUDAR}_{1}$

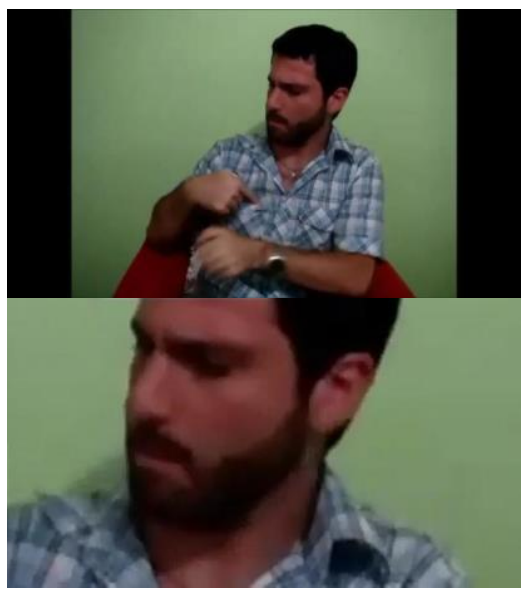

$\mathrm{IX}_{1}$ 


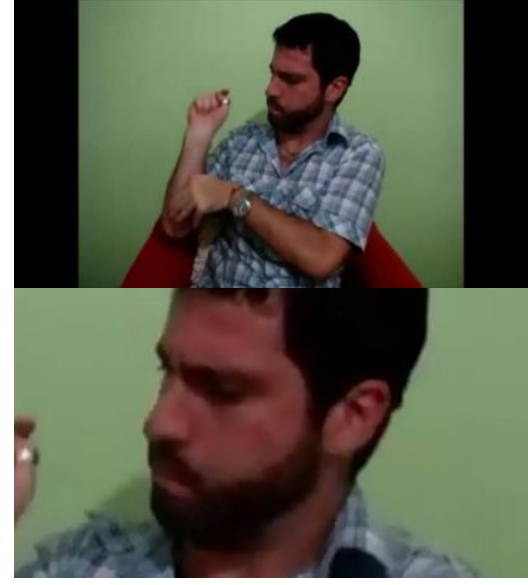

FERROAR $_{2}$

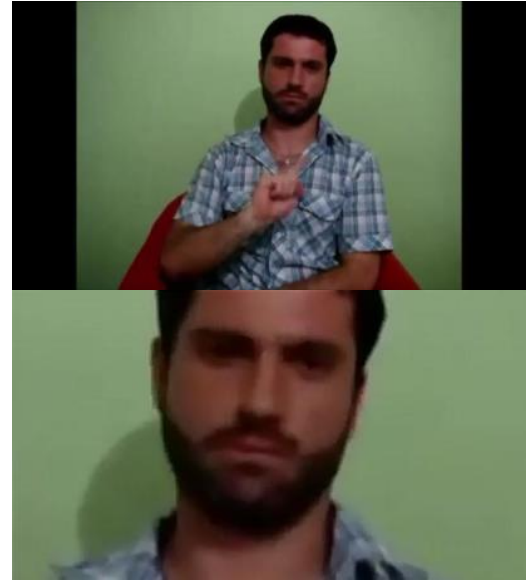

NÃO

Fonte: elaborada pelos autores.

Imagens retiradas do vídeo "O Escorpião e a tartaruga", de Rimar Segala com sua permissão.

Já no trecho 11, percebe-se que não há a sinalização da partícula SI. A condicional é marcada pelo levantamento das sobrancelhas, que, por sua vez, apresenta o escopo descrito na literatura: este espraia-se apenas sobre a oração da condição.

\subsection{CONSTRUÇÕES RELATIVAS}

Nenhuma ocorrência de relativa foi observada no vídeo "O escorpião e a tartaruga", porém foi observada 1 construção relativa no vídeo "Aprende a escrever na areia".

\section{Trecho 12:}

LUGAR IX IX 1 SALVAR M-U-S-S-A $_{\text {ls }}$
Lit.: lugar este eu salvei Mussa
'(n)este lugar que eu salvei o Mussa'.

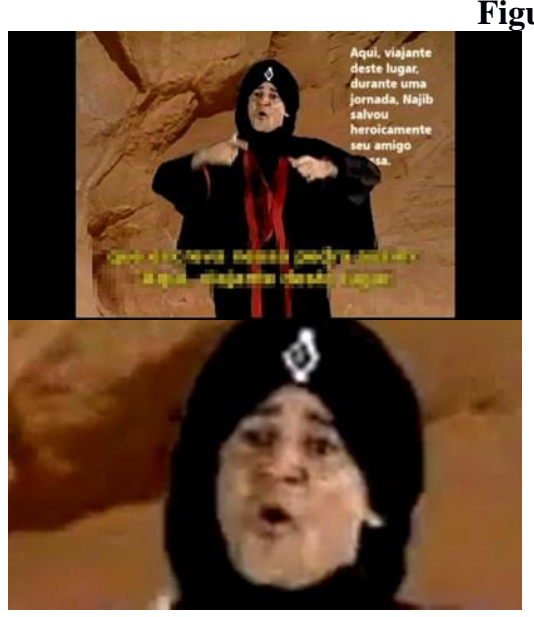

LUGAR

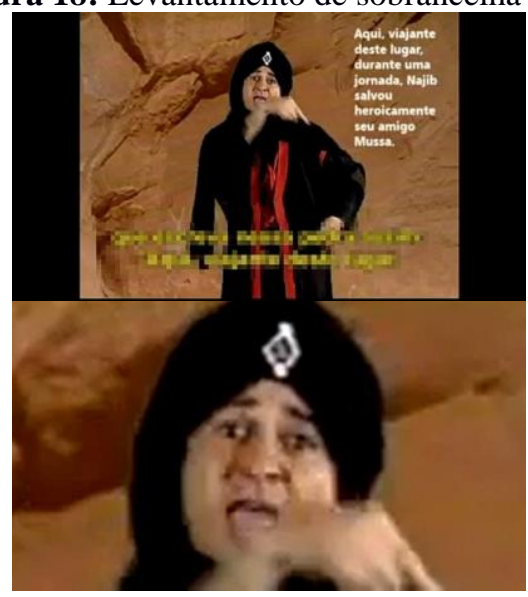

$\mathrm{IX}_{\mathrm{a}}$

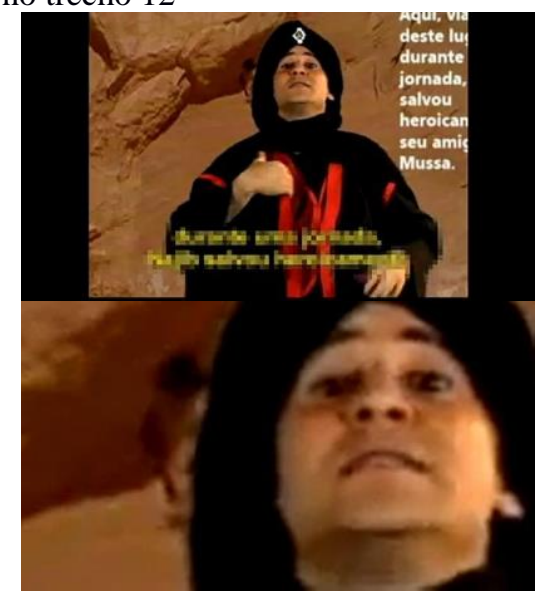

$\mathrm{IX}_{1}$ 


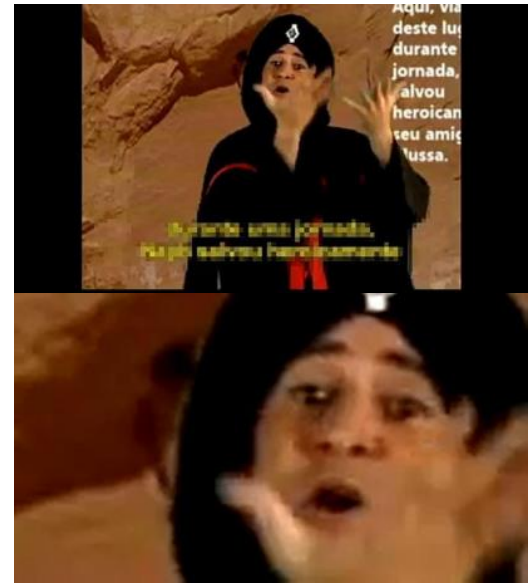

SALVAR

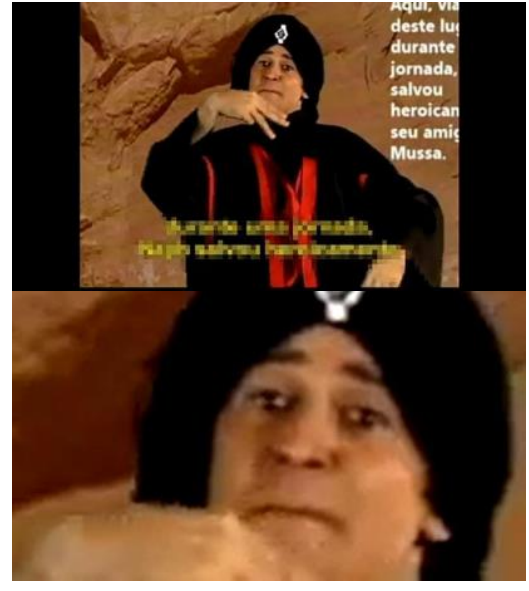

M-U-S-S-A

Fonte: elaborado pelos autores.

Imagens retiradas do vídeo "Aprende a escrever na areia" (TV INES).

É interessante observar que nas orações relativas, o levantamento da sobrancelha ocorre tanto na oração relativa (IX 1 SALVAR MUSSA) quanto no nominal que é modificado por ela (LUGAR IX $)_{a}$ ). Este é o mesmo comportamento observado por Branchini e Donati, (2009) na LIS.

\subsection{OUTRAS OCORRÊNCIAS}

Por fim, a análise dos vídeos trouxe outras ocorrências de uso da sobrancelha que merecem ser citadas. É preciso deixar claro, contudo, que os usos descritos abaixo são apenas construções identificadas nos vídeos em questão e que mais estudos são necessários para determinar se estas realmente ocorrem nos contextos sintáticos descritos abaixo.

Primeiramente, houve um grande número de marcações não-manuais dentro do DP/NP (sintagma determinante/sintagma nominal). Na maioria delas a sobrancelha foi articulada junto ao pronome ou determinante indexical (IX) que se referenciava a algo ou alguém. Esta marca aparece também na forma dual do pronome indexical $\left(\mathrm{IX}_{\mathrm{A}-\mathrm{B}}\right)$. Exemplos são fornecidos a seguir:

Figura 19. Levantamento de sobrancelha em contextos de IX.

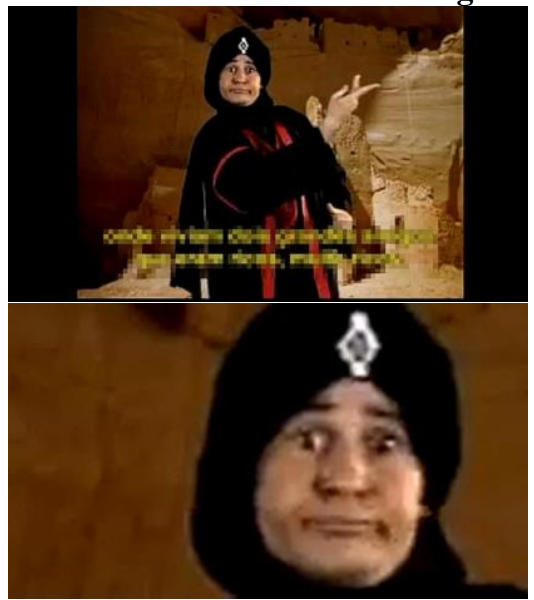

$\mathrm{IX}_{\mathrm{A}-\mathrm{B}}$

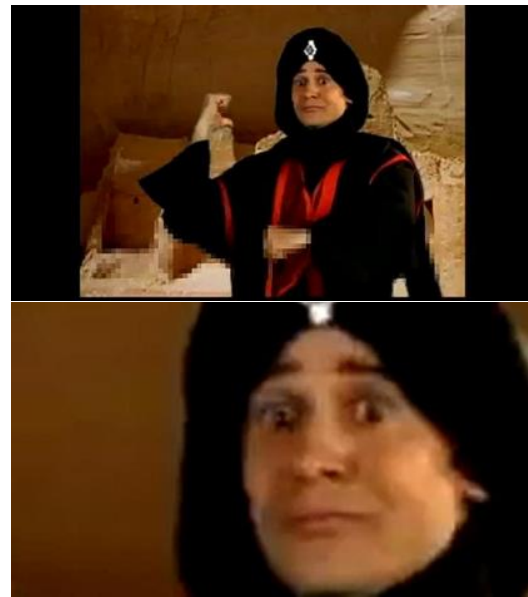

$\mathrm{IX}_{\mathrm{BACK}}$

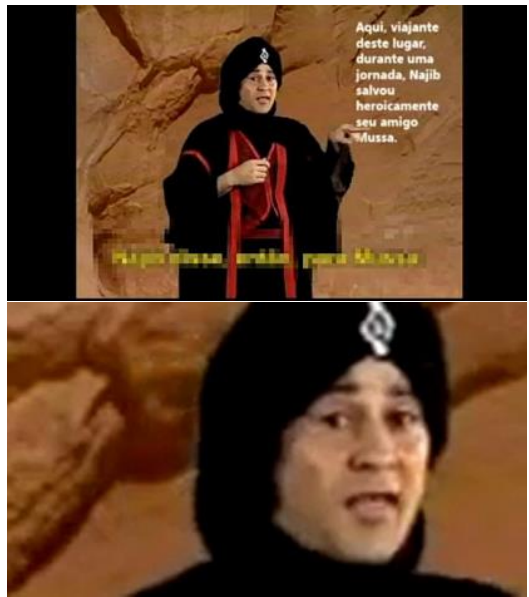

$\mathrm{IX}_{\mathrm{A}}$

Fonte: elaborado pelos autores.

Imagens retiradas do vídeo "Aprende a escrever na areia” (TV INES) 
Outro contexto de levantamento de sobrancelha foi identificado no vídeo "O escorpião e a tartaruga" com o sinal que aqui foi glosado como ENUMERAÇão. É um sinal utilizado para se introduzir uma lista de elementos e que, parece-nos, ter uma função coordenativa.

Figura 20. Levantamento de sobrancelha com sinal ENUMERAÇÃO.
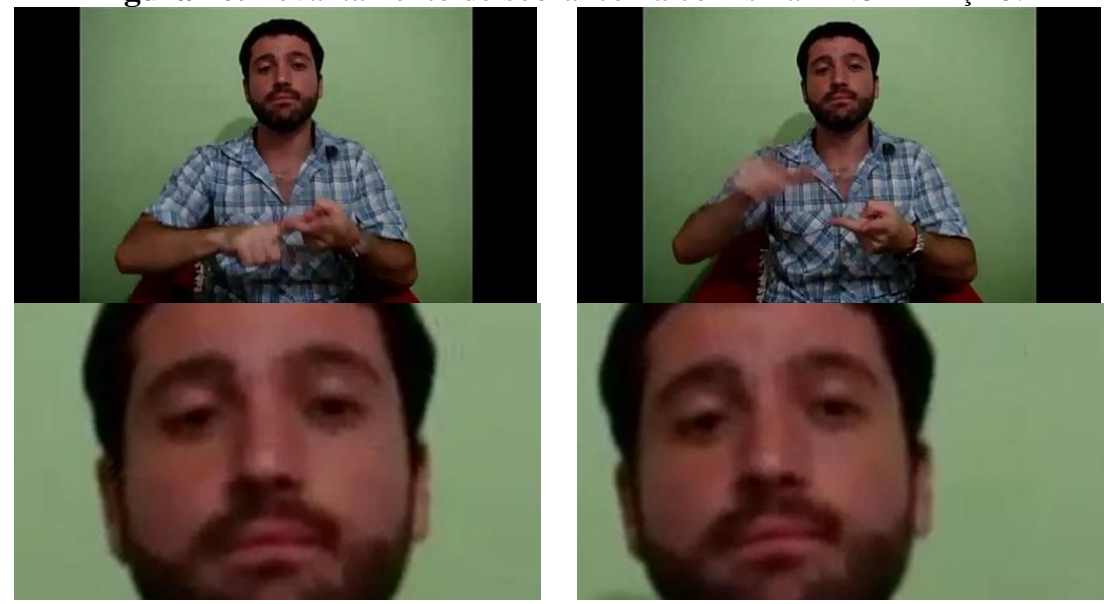

ENUMERAÇ̃̃O

Fonte: elaborado pelos autores.

Imagens retiradas do vídeo "O Escorpião e a tartaruga”, de Rimar Segala, com sua permissão.

Além dessas, houve duas outras ocorrências muito interessantes. A primeira foi o levantamento da sobrancelha para marcar orações subordinadas adverbiais, que nos parecem ser adverbiais temporais. Esse uso foi identificado no vídeo "O escorpião e a tartaruga". As sentenças são fornecidas a seguir:

8) $\langle\text { TARTARUGA-ANDAR }\rangle_{\mathrm{CL}}$ RIO ÁGUA $\langle\text { QUASE-ENTRANDO-NO-RIO }\rangle_{\mathrm{CL}}$ ESCORPIÃO DESESPERADO

'A tartaruga estava andando até o rio. Quando estava quase entrando na água, havia um escorpião desesperado.'

Figura 61: Levantamento de sobrancelha com a construção 〈QUASE-ENTRANDO-NO-RIO ${ }_{\text {CL. }}$.

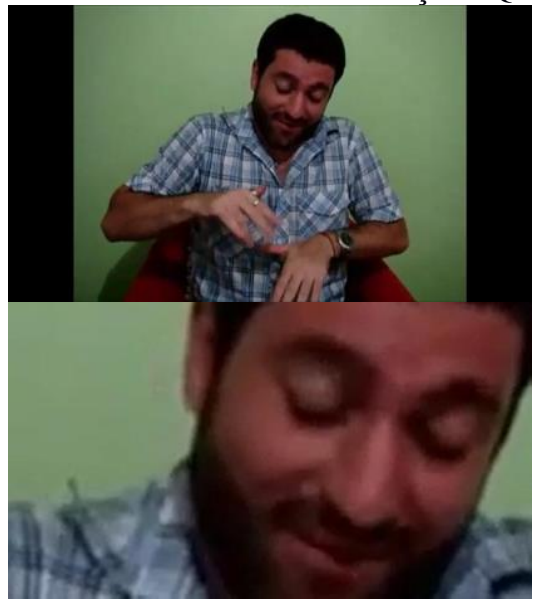

$\langle\text { QUASE-ENTRANDO-NO-RIO }\rangle_{\mathrm{CL}}$

Fonte: elaborado pelos autores.

Imagens retiradas do vídeo "O Escorpião e a tartaruga", de Rimar Segala, com sua permissão 
9) <CHEGAR-NA-MARGEM-DO-RIO> ${ }_{\text {CL+DEVAGAR ESCORPIÃO PICAR }}$

'Quando finalmente chegaram à margem do rio, o escorpião picou (a tartaruga).'

Figura 22. Levantamento de sobrancelha com a construção <CHEGAR-NA-MARGEM-DO-RIO>.

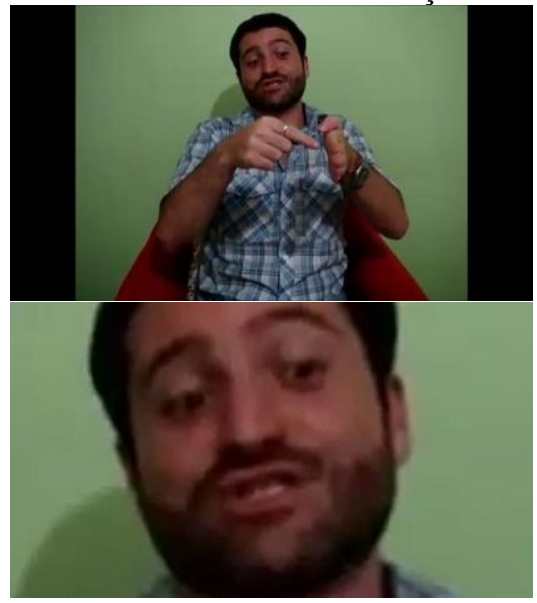

<CHEGAR-NA-MARGEM-DO-RIO>

Fonte: elaborado pelos autores.

Imagens retiradas do vídeo "O Escorpião e a tartaruga”, de Rimar Segala, com sua permissão.

O outro uso da sobrancelha como ENM sintática nos vídeos foi para marcar pequenos trechos que podemos, inicialmente, classificar como apostos, uma vez que parecem ter uma função explicativa ou até mesmo especificadora. É o que se observa no exemplo a seguir do vídeo "Aprende a escrever na areia":

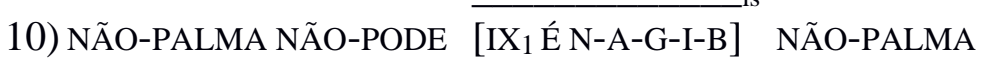

'Não, não pode, disse Nagib. Não!'

Figura 23. Levantamento de sobrancelha com a construção de aposto.

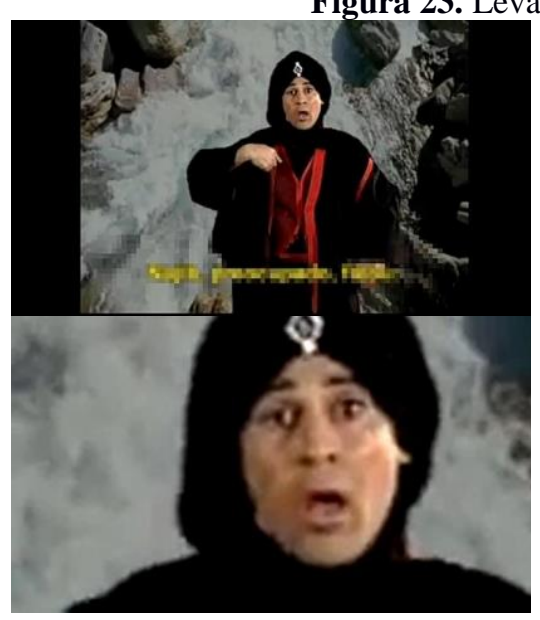

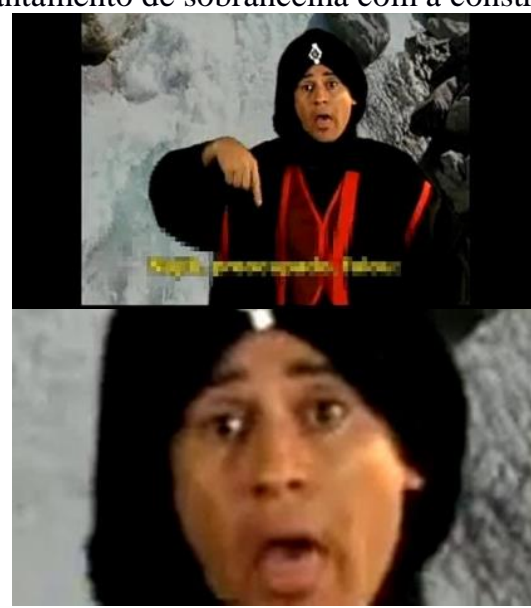

Fonte: elaborado pelos autores.

Imagens retiradas do vídeo "Aprende a escrever na areia" (TV INES).

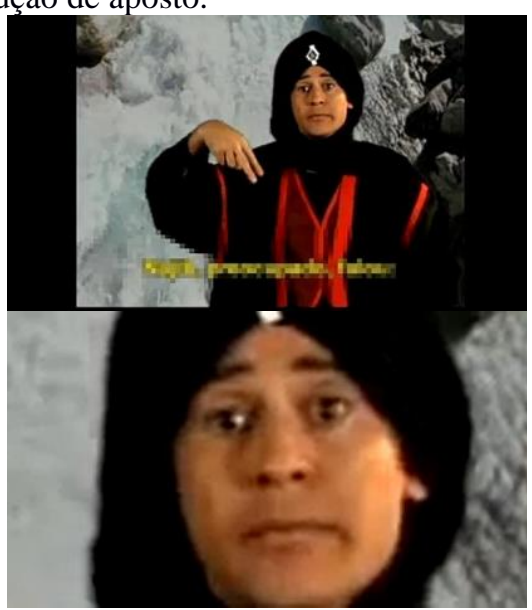




\section{CONSIDERAÇÕES FINAIS}

O objetivo deste trabalho foi o de investigar o uso das sobrancelhas como marcadores sintáticos na Língua Brasileira de Sinais. O que se esperava era que, através das análises, os cinco usos sintáticos desse articulador fossem confirmados, a saber: i) construções de tópico; ii) interrogativas do tipo S/N; iii) interrogativas do tipo QU-; iv) condicionais; e v) orações relativas.

Adicionalmente, as análises revelaram outros usos da sobrancelha como ENM sintática, de modo que esse marcador aparece também em pronomes e determinantes indexicais (ix), em contextos de enumeração, em orações adverbiais e em construções que se assemelham a apostos. É importante ressaltar, porém, que essas ocorrências precisam ser verificadas em mais dados linguísticos, dada a limitação de nosso estudo.

Por fim, é interessante observar que o movimento de sobrancelhas não está associado a uma única estrutura sintática. Mas sim, aparece como um verdadeiro delimitador de domínios sintáticos. Dessa forma, tornam-se necessárias novas investigações que discutam o estatuto teórico desse tipo de marcador, enquanto um epifenômeno das línguas de sinais.

\section{Referências}

AARONS, Debra. Aspects of the syntax of American Sign Language. 200f. Dissertação de Doutorado. Boston University, 1994.

BRANCHINI, Chiara; DONATI, Caterina. "Italian Sign Language Relatives: A Contribuition to the Typology of Relativization Strategies". In: LIPTÁK, Anikó (org). Correlatives CrossLinguistically. Amsterdã: John Benjamins Publishing Company, 2009.

DACHKOVSKY, Svetlana. "Facial expression an intonation in Israeli Sign Language. The case of neutral and counterfactual conditionals". In: QUER, J. (Ed.). Signs of the time: Selected papers from TISLR 2004. Hamburg: Signum, 2008, p. 61-82.

DACHKOVSKY, Svetlana et al. Signers' perception of conditional intonation: A comparative study of Israeli Sign Language and German Sign Language, 2015. Disponível em:

http://www.iatl.org.il/wpcontent/uploads/2015/06/IATL31abstract_Dachkovsky_et_al.pdf . Acesso em: 24 jan. 2017.

LOURENÇO, Guilherme. Layering de informações visuais e a estrutura morfofonológica dos verbos em Libras In: II Congresso Nacional de Pesquisas em Linguística e Libras, Florianópolis, 2018.

LOURENÇO, Guilherme; WILBUR, Ronnie B. Are plain verbs really plain?: Co-localization as the agreement marker in sign languages. FEAST. Formal and Experimental Advances in Sign language Theory. v.2, 2018, p.68-81.

PFAU, Roland; QUER, Joseph "Nonmanuals: their grammatical and prosodic roles". In: BRENTARI, Diane (org). Sign Languages. Cambrigde: University Press, 2010.

QUADROS, Ronice Müller de. Gramática das Línguas Gestuais. Lisboa: Universidade Católica Editora, 2011.

QUADROS, Ronice Müller de; KARNOPP, Lodenir Becker. Língua de sinais brasileira: estudos linguísticos. Porto Alegre: Artmed, 2004. 
SEGALA, Rimar R. (2009) Escorpião e tartaruga - Rimar R. Segala e Sueli Ramalho. [arquivo de video]. Disponível em: https://www.youtube.com/watch?v=qHZDpPps9Zg . Acesso em: 24 jan. 2017.

TV INES. Aprende a escrever na areia. 2014. (6min27s). Disponível em: <http://tvines.org.br/?p=5765\&paged=11>. Acesso em: 30 maio 2019.

WILBUR, Ronnie B. "Modality and the Structure of Language: sign languages versus signed systems". In: MASCHARK, Marc; SPENCER, Patricia Elizabeth (org). Oxford handbook of deaf studies, language, and education. Nova York: Oxford University Press, 2003.

Lorena Mariano Borges Figueiredo, lorenambfigueiredo@gmail.com

Guilherme Lourenço guilhermelourenco@ufmg.br

Recebido em: 23 fev. 2019

Aceito em: 28 Abril. 2019

Publicado em: Junho de 2019 